Originalveröffentlichung in: Brüllmann, Philipp ; Rombach, Ursula ; Wilde, Cornelia (Hrsgg.): Imagination, Transformation und die Entstehung des Neuen, Berlin 2014, S. 111-154 (Transformationen der Antike ; 31)

\title{
trovare cose non vedute. Naturnachahmung und Phantasie in Cennino Cenninis Libro dell'arte
}

\author{
PETER SEILER
}

\begin{abstract}
Anima enim facit novas compositiones, licet non faciat novas res; et secundum quod fingit interius, sic etiam depingit et sculpsit exterius Bonaventura, 3 Sent. 37 , dubitum $1^{1}$
\end{abstract}

Ceninno Cenninis Libro dell'arte gilt als früher Vorbote einer Theorie der Malerei, die den Begriff der Phantasie als einer Fähigkeit, die Neues bildet, ins Zentrum stellt. ${ }^{2}$ Als Beleg fungiert ein Passus aus dem ersten Kapitel:

[...] e quest'è un'arte che ssi chiama dipingere, che conviene avere fantasia e hoperazione di mano, di trovare cose non vedute, chacciandosi sotto ombra di naturali, $e$ fermarle con la mano, dando a dimostrare quello che nonne sia. E con ragione merita metterla a ssedere in secondo grado alla scienza e choronarla di poexia. La ragione è questa: che'l poeta, con la scienza, per una che à, il fa degnio e 'llibero di potere comporre e llegare insieme sì e nno come gli piacie, secondo suo volontà. Per lo simile, al dipintore dato è libertà potere comporre una figura ritta, a sedere, mezzo huomo mezzo cavallo, si chome gli piace, secondo suo' fantasia. ${ }^{3}$

* Liouba Popoff danke ich für engagierte und kompetente Hilfe bei der Literaturbeschaffung, Ursula Rombach für Verbesserungen und Ergänzungen der Übersetzungen lateinischer Textstellen und eine mehrfache kritische Lektüre des Textes.

1 Flasch (1965), 295, Anm. 122. Bonaventura, Comm. in III. lib. Sent. dist. 37, dub. 1, hier: Bd. 3.

2 Schlosser (1924), 79: „Cennini (führt) sehr merkwürdigerweise einen Faktor ein, der seine Kunst schon der unsrigen nähert, freilich schon in der Spekulation des späten Altertums seine Rolle spielt: die künstlerische Phantasie«. Vesco (1919), 71; Venturi (1925), 239; Prandi (1962), 364-365; Venturi (1964), 91; Boscovits (1973), 206 und 222; Kemp (1977), 369: „Cennini's remarkable exploitation of fantasia almost certainly takes its immediate inspiration from medieval rather than first-hand classical sources. [...] possible medieval sources for Cennini's ideas in no way diminish the precocity and novelty of his far-reaching claims.« Magagnato (1982), X-XII; Summers (1981), 37-38, 133; Gramaccini (1985), 202-203; Kemp (1997), 131 und 309-310; Warnke (1997), 259-260; Serchi, in: Cennini, Il libro dell'arte/Ed. Serchi (1999), 8; Kruse (2000), 309; Eusterschulte (2000), 798-799; Belting (2001a), 145; Wolf (2002), 236237; Kruse (2003), 81; Klier (2004), 54; Klier (2007), 18-20; Kruse (2010), 289-292.

3 Cennini, Il libro dell'arte/Ed. Frezzato (2008), 62. 
[...] und das ist eine Kunst, die man Malerei nennt, der es zukommt, Phantasie und Tätigkeit der Hand zu haben, um nicht gesehene Dinge zu finden, die sich unter dem Schatten der natürlichen (Dinge) verbergen, und um diese mit der Hand festzuhalten, und auf diese Weise zu zeigen, was nicht ist. Und mit Recht verdient sie (die Malerei) auf der zweiten Stufe (nach) der Wissenschaft zu sitzen und mit Poesie gekrönt zu werden. Der Grund ist dieser: dass der Dichter mit der Wissenschaft - deswegen hat er eine - würdig und frei ist, ja und nein zusammenzusetzen und verbinden zu können, wie es ihm gefällt, seinem Willen folgend. Auf ähnliche Weise ist dem Maler Freiheit gegeben, eine Figur zusammenzusetzen, aufrecht, sitzend, halb Mensch, halb Pferd, so wie es ihm gefällt, nach seiner Phantasie. ${ }^{4}$

Der Passus, der häufig als Cenninis »Malereidefinition« bezeichnet wird, enthält eine Reihe von Verständnisschwierigkeiten, die nicht zuletzt anhand der zahlreichen divergierenden Übersetzungen und Kommentierungen deutlich werden. Da diese aber gleichwohl in der vorherrschenden Gesamteinschätzung konvergieren, werden sie zumeist übergangen. Allen Interpretationen ist die Auffassung gemein, dass Cennini durch die Verbindung von fantasia und operazione di mano den Kerngedanken seines Malereiverständnisses zum Ausdruck bringt ${ }^{5}$ und dass er mit allem Nachdruck der kreativen Seite künstlerischen Schaffens (Erfindungsgabe und Erfindungsfreiheit) eine zentrale Rolle einräumt.

Ein genereller Konsens besteht auch darin, dass antike Referenztexte für Cenninis Malereiverständnis relevant waren. Um welche es sich handelte und ob sich Cennini ihre Inhalte direkt durch eigene Lektüre oder durch indirekte Vermittlung aneignete, wird unterschiedlich beantwortet. Genannt werden Aristoteles, ${ }^{6}$ Philostrat, ${ }^{7}$ Horaz, ${ }^{8}$ Quintilian ${ }^{9}$ und Plinius ${ }^{10}$.

Im Folgenden soll gezeigt werden, dass der Status, den Cennini der Phantasie einräumt, deutlich geringer ist als gemeinhin angenommen und seine Ausführungen zur Erfindungsfreiheit des Malers nicht ausreichen, um ihn als Vorläufer moderner Vorstellungen künstlerischer Kreativität einzustufen.

Bereits die unmittelbar vorausgehenden Formulierungen, vor allem aber auch seine Äußerungen über verstandesgemäße, richtige Naturnachahmung geben

4 Cennini, Il libro dell'arte, Übers. Löhr (2008), 10 (mit Änderungen).

5 Zuletzt Gründler (2010), 74: »Es war Cennino Cennini, der die Phantasie in seinem Libro dell'arte zu Beginn des 15. Jahrhunderts positiv konnotierte und sie zum Ausgangspunkt der künstlerischen Tätigkeit werden ließ.« Kruse (2010), 289: »Die arte di dipingere erfordert zuallererst Vorstellungsvermögen (fantasia), ein Begriff den Cennini als erster nachantiker Autor in die Theorie der Malerei einführt [...].«

6 Gramaccini (1985), 206; Kruse (2000), 310; Eusterschulte (2000), 798; Kruse (2010), 291, Anm. 47.

7 Kruse (2003), 75, Anm. 66.

8 Schlosser (1924), 80; Venturi (1925), 239; Magagnato (1982), X-XI; Bolland (1996), 469; Pardo (1997), 44, Anm. 18; Kruse (2000), 313; Eusterschulte (2000), 799; Pfisterer (2002a), 262; Kruse (2003), 75, 80 und 132; Kruse (2010), 291.

9 Venturi (1925), 239; Venturi (1964), 91; Kruse (2000), 309; Kruse (2003), 74-75; Kruse (2010), 289-290, 291 Anm. 48.

10 Gramaccini (1985), 206-207; Kruse (2000), 309-310; Kruse (2003), 74; Kruse (2010), 290. 
Anlass zu einer erneuten Lektüre des Libro und zur Revision der bisherigen Kommentierungen seines Malereiverständnisses.

Der aus Colle Val d'Elsa stammende Maler fokussiert im ersten Kapitel seines Libro dell'arte nicht nur das Zusammenwirken von Phantasie und Hand als "Ausgangspunkt der künstlerischen Tätigkeit«. ${ }^{11}$ Die Malerei wird im Libro als wissensbasierte Kunst (scienza) präsentiert. Cennini reklamiert nacheinander zwei Erfordernisse für ihre Ausübung, wobei er jeweils dieselbe Wendung (»la quale conviene aver «) benutzt: an erster Stelle nennt er die Verbindung von Wissen und Handtätigkeit und erst an zweiter die Verbindung von Phantasie und Handtätigkeit. Im Anschluss an den Sündenfall und die Vertreibung der Stammeltern aus dem Paradies schildert Cennini die Einführung der arti bisognevoli, die einerseits alle auf der scienza (Philosophie) basieren, aber sich andererseits hinsichtlich ihres größeren oder kleineren Wissens (scienza) auch unterscheiden:

Onde cognoscendo Adam il difetto per lui commesso, esendo dotato da Dio si nobilmente si come radice, principio e padre di tutti noi, rivenne di sua scienza di bisogno era trovare modo da vivere manualmente; e chosi egli incominciò con la zappa e Eva col filare; poi seguitò molt'arti bisognevoli e diferenziate l'una dall'altra, e fu ed è di magiore scienzia l'una che l'altra, ché tutte non potevano essere uguali: perché la più degnia è la scie[n]zia; apresso di quella, seghuitò alchune discendentii da quella, la quale conviene avere fondamento da quella, chon operazione di mano; e quest'è un'arte che ssi chiama dipingere, che conviene avere fantasia e hoperazione di mano $[\ldots]^{12}$

Als nun Adam den von ihm begangenen Fehler erkannte und weil er von Gott als unser aller Wurzel, Ursprung und Vater so großzügig begabt worden war, kam er durch seine Weisheit darauf, dass es nottat, ein Mittel zu finden, um von der Arbeit Hände zu leben. Und so begann er mit dem Spaten und Eva mit dem Spinnen; danach ließ er viele notwendige und voneinander verschiedene Kunstfertigkeiten folgen, und es war und ist eine von größerem Wissensgehalt als die andere, denn alle konnten nicht gleich [darin] sein, denn die eine Wissenschaft ist die würdigste. Neben dieser folgt eine, welche von ihr abstammt, und ihrer als Grundlage bedarf, sowie der Tätigkeit der Hand; und das ist eine Kunst, die man Malerei nennt, für die es der Fantasie bedarf und des Hand-Werks [...]. ${ }^{13}$

Die Wissenschaft der Malerei (scienza), die der Philosophie (la scienza) ${ }^{14}$ ihr Fundament verdankt und mit der Handtätigkeit (operazione di mano) verknüpft ist, erfordert Intellekt. Vom Intellekt (intelletto) und vom Verstand (ragione) des Malers ist im Libro dell'arte häufiger die Rede als von seiner Phantasie

11 Gründler (2010), 74.

12 Cennini, Il libro dell'arte/Ed. Frezzato (2008), 62.

13 Cennini, Il libro dell'arte/Übers. Löhr (2008), 10.

14 Zur Bedeutung der Philosphie als der das durch die verschiedenen (freien) Künste erwerbbare Wissen vereinenden Wissenschaft sowie zu der Vorstellung der Stufen philosophischen Wissens siehe Kobusch (1989), 634 und bes. 637 zu Hugo von St. Viktor, der auch die mechanischen Künste einbezieht sowie Kruse (2000), 308 und Kruse (2003), 73 (mit Hinweis auf Brunetto Latini). 
(fantasia). Das zur Ausübung der Malerei erforderliche Wissen wird in den Kapiteln 5-189 in zahlreichen technischen Verfahren und Rezepten mit verstandesgemäßen Begründungen (ragioni) ausführlich dargelegt. Von der Phantasie bzw. von der Verbindung von Phantasie und Handtätigkeit ist dagegen nur noch an drei weiteren Stellen explizit die Rede (Kap. 27, 140, 173). ${ }^{15}$ Die nächstfolgende Stelle befindet sich in Kap. 27, d.h. innerhalb der Kapitelserie, die dem Zeichnen gewidmet ist und in der Cennini auch seine Auffassungen über Naturnachahmung darlegt (vor allem in Kap. 28). Die beiden übrigen betreffen das Zeichnen von Figuren in Vergoldungen und die Gestaltung von Farbkontrasten.

Die Begrenzung der »Malereidefinition « Cenninis auf den eingangs zitierten Passus und die mit ihr einhergehende Ausblendung von Zeichnung (disegno), Naturnachahmung (ritrarre sempre del naturale) und Verstand (ragione, intelletto) ist die Hauptursache für die gängige Überbewertung der Phantasie bzw. ihrer kreativen (vermeintlich moderne Vorstellungen antizipierenden) Faktoren.

\section{Erfindung und Naturnachahmung}

Bereits früh hat man versucht, Unklarheiten, die mit Cenninis teils umständlichen, teils stark verkürzten, teils durch begriffliche Mehrdeutigkeiten belasteten Formulierungen verbunden sind, semantisch zu präzisieren, wobei sich die Formulierungsvorschläge mitunter von dem tatsächlichen Wortlaut erheblich entfernten. Im deutschsprachigen Raum hat Albert Ilg mit seiner Übersetzung noch heute gängigen Vereinfachungen vorgearbeitet. ${ }^{16}$ Ilg übersetzte $» d i$ trovare cose non vedute « mit »um nie gesehene Dinge zu erfinden $«,{ }^{17}$ und deutete den Vorgang dadurch als Akt reiner Neuschöpfung, obwohl der unmittelbar folgende Nebensatz (»chacciandosi sotto ombra di naturali«) seinem Wortlaut nach auf bereits vorhandene $»$ Dinge $\ll$ hinweist, die aufgrund ihres Verborgenseins unter naturgemäßen Schatten ungesehen sind und nur mit der Hilfe von Phantasie und Handtätigkeit erfasst werden können (»conviene avere fantasia e hoperazione di mano di trovare cose non vedute [...] e fermarle con la mano«). Ohne die Frage aufzuwerfen, was Cennini mit (ungesehenen) Dingen konkret gemeint haben könnte, fasste

15 Cennini, Il libro dell'arte/Ed. Frezzato (2008), 80, 162, 197.

16 Cennini, Il libro dell'arte/Übers. Ilg (1888), 4: »[...] weil die Weisheit das Allerwürdigste ist. Eine von dieser herkommende, welche auf ihre Grundlagen samt der Ausführung mit den Händen zurückzielt, ist eine Kunst, welche man Malerei nennt, welche zugleich mit der Ausführung der Hand Phantasie erfordert, um nie gesehene Dinge zu erfinden (indem man sie in die Hülle des Natürlichen steckt) und sie mit der Hand festzuhalten, indem als wirklich vorzustellen ist, was nicht vorhanden.«

17 Cennini, Il libro dell'arte/Übers. Ilg (1888), 4; ebenso von: Dresdner (1968), 52; Kruse (2000), 308 und 309: »Im ersten Teil der Definition wird die Malerei als kreativer medialer Prozess definiert«; Kruse (2003), 73; Krüger (2001), 42 und 123; Wolf (2002), 237; Pfisterer (2002), 271; Pfisterer (2002a), 262; Kruse (2010), 289 - In der englischsprachigen Literatur findet man dagegen die u.a. in Cennini Ed. Thompson (1960), 1 vorhandene Übersetzung »to discover things not seen.« 
Ilg den erläuternden Attributivsatz »chacciandosi sotto ombra di naturali« als Hinweis auf ein Darstellungsverfahren für erfundene Dinge auf. Durch seine Übersetzung »indem man sie in die Hülle des Natürlichen steckt $\aleph^{18}$ präsentierte er das natürliche Verborgensein der Dinge als einen aktiven Vorgang des Verhüllens der Dinge durch den Maler, wobei er unter »Hülle des Natürlichen « (ombra di naturali) ganz allgemein die Erscheinungsformen (sichtbarer, vorhandener) natürlicher Dinge meinte. Das zeigt auch seine Übersetzung des letzten Teils des Satzes, dem er, nicht zuletzt aufgrund des bis vor wenigen Jahren in allen Editionen gebotenen Wortlauts (»dando a dimostrare quello che non è, sia« statt »quello che nonne sia«), ${ }^{19}$ glaubte, eine bezüglich ihres ontologischen Gehalts letztlich unklare Aussage über die angestrebte illusionistische Wirkung malerischer Erfindungen entnehmen zu können (»indem als wirklich vorzustellen ist, was nicht vorhanden «). ${ }^{20}$ Nach Ilgs Übersetzung hätte Cennini die Malerei als ein bildliches Darstellungsverfahren aufgefasst, das der integumentalen Poetik entspricht, ${ }^{21}$ und zugleich eine Bildwirklichkeit mit eigenem ontologischem Anspruch generiert. ${ }^{22}$

Die Vorstellung der Malerei als Medium einer mit Hilfe produktiver Phantasietätigkeit generierten poetischen Scheinwelt, einer Malerei, die sich nur äußerlich, lediglich um den Effekt der Wirklichkeitsillusion zu erzielen, an den sichtbaren Dingen der Natur orientiert, im Wesentlichen aber über eine umfassende, an Naturwahrheiten nicht gebundene poetische Lizenz verfügt, glaubte auch Venturi Cenninis »Malereidefinition« entnehmen zu können:

18 Ebenso Brunello, in: Cennini, Il libro dell'arte/Ed. Magagnato/Brunello (1982), 4, Anm. 1; Pardo (1997), 44; Krüger (2001), 42 und 123; Pfisterer (2002), 271 und Pfisterer (2002a) mit modifizierter Übersetzung; Wolf (2002), 237. Thompson, in: Cennini, Il libro dell'arte/Ed. Thompson (1960), 1, übersetzt korrekt: »things not seen, hiding themselves under the shadow of natural objects«; ebenso Kruse (2000), 308: »Dinge [...], welche sich im Schatten der natürlichen Dinge verbergen (cacciandosi sotto ombra di naturali)«. Löhr (2008c), 167 kommentiert: »Sembra trattarsi [...] di un processo dell'evidenza che mostra anche ciò che esiste nella natura in modo latente e che prima non era visibile. Questo passo resta comunque di difficile comprensione.« Wenig sinnvoll ist die Annahme von Gramaccini (1985), 202, derzufolge »Zufallsbilder« in die Kategorie »nicht gesehene Dinge, die sich unter dem Schatten der natürlichen verbergen « gehören.

19 Vgl. hierzu Cennini, Il libro dell'arte/Ed. Frezzato (2008), 62 mit Anm. 1. Zu dieser Emendation vgl. Anm. 36.

20 Cennini, Il libro dell'arte/Übers. Ilg (1888), 4.

21 Vgl. hierzu die in dieselbe Richtung gehenden Interpretationen von Pardo (1997), 44; Krüger (2001), 39-42; Wolf (2002), 237.

22 Vgl. Kemp (1997), 131 und 310: »man fixiert und gestaltet mit der Hand Dinge, die man nicht mit Augen sah, und stellt sie als wirklich existierend dar, indem man ihnen den Schein des Natürlichen gibt«; Summers (1981), 41-55, bes. 51: »Thus by definition painting has the positive paradoxical goal of creating illusion in the full awareness that it is illusion.« Kruse (2000), 309, glaubte »eine mittelalterliche Ontologie der Malerei im Stile des Alanus de Insulis« feststellen zu können«, vgl. auch 311-312; ebenso Kruse (2003), 74; Krüger (2001), 123 (»das, was nicht ist, darzubieten, als sei es«; Wolf (2002), 237; Pfisterer (2002a), 263: »(man) stellt so das eigentlich Nicht-Existente als wirklich dar, indem man ihm den Schein des Natürlichen gibt«. Kruse (2003), 77. Zu Kruses problematischer Interpretation der Äußerungen des Alanus ab Insulis über Malerei siehe Anm. 39. 
Questa definizione [...] grandeggia ne'secoli. Bisogna creare come la natura crea (cacciandosi sotto ombra di naturali) e non imitare ciò che la natura ha creato; anzi bisogna creare ciò che non si è mai veduto in natura (trovare cose non vedute). Bisogna illudere, bisogna che la fantasia si faccia realtà per l'illusione: ma bisogna pur sempre che l'arte rimanga realità fantastica. Per giungere a tanto Cennino può essere stato

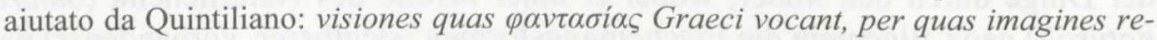
rum absentium ita repraesentantur animo, ut eas cernere oculis ac praesentes habere videamur [VI,2,29]. Eppure, anche se l'influsso di Quintiliano sul Cennini fu reale, quale importanza nuova è assegnata all'idea applicandola alla pittura anzi che alle visioni! Una semplice osservazione di un fenomeno naturale diventa definizione di un'attività spirituale. A traverso tutto il Rinascimento non c'è più una voce così alta, una coscienza così cristallina del carattere creativo dell'arte. Sembra che un occhio vergine si affacci alla realità: mantiene l'idealità del passato e l'imprime nella realità che scopre, mantiene una sintesi che poi si sperderà. È così definita dal Cennini non l'arte in generale, ma un'arte che gli è cara: l'arte di Giotto. ${ }^{23}$

Venturi glaubte, mit der Formulierung »creare come la natura crea (cacciandosi sotto ombra di naturali) e non imitare ciò che la natura ha creato«, eine radikal neue, in der Renaissance nur zögerlich anerkannte Erweiterung der Lizenz der Phantasie beschreiben zu könnnen, obwohl Cennini sich mit allem Nachdruck zum Zeichnen nach der Natur (ritrarre sempre dal naturale) bekannte. ${ }^{24}$ Panofsky gelangte in seiner ein Jahr zuvor publizierten Studie Idea zu einer diametral entgegengesetzten Einschätzung. Er betonte, dass im Libro dell'arte Naturnachahmung »nicht nur im Sinne einer Parallelisierung«, sondern auch »im Sinne einer Bezugsetzung aufgefasst « wurde. ${ }^{25}$ Anders als Venturi sah er Cennini vorrangig als Protagonisten dieser neuen künstlerischen Einstellung zur Natur, deren Etablierung man bereits im 14. Jahrhundert vor allem als historische Leistung Giottos auffasste. ${ }^{26}$ Panofsky rekurrierte allerdings nicht auf das Kap. 1 des Libro dell arte, sondern auf das Kap. 88 (»El modo del ritrarre una montagnia del naturale $\ll)$ :

Se vuoi pigliare buona maniera di montagnie e cche paino naturali, togli di pietre grandi, che sieno scogliose e non pulite; e rritra'ne del naturale, daendo i lumi e schuro secondo che lla ragione t'acchonsente. ${ }^{27}$

Wenn du Gebirge in einer guten Weise zeichnen willst, welche natürlich scheinen, so nimm große Steine, rau und unpoliert. Und zeichne sie nach der Natur, indem du ihnen Licht und Schatten verleihst, je nachdem es Dir der Verstand erlaubt. ${ }^{28}$

23 Venturi (1925), 239; ebenso Venturi (1964), 91; Magagnato (1982), XII; Chastel (1977), 32: winterpretation naivement $>$ moderniste $\ll$

24 Dabei hat Venturi (1925), 240, Cenninis Forderung der Naturnachahmung durchaus wahrgenommen.

25 Panofsky (1975), 22. Zur »imitatio naturae als Strukturanalogie« siehe auch Flasch (1965), 282284 und 304-305 (mit kritischen Einschänkungen zu Panofskys Auffassungen).

26 Bialostocki (1963/1988), 65.

27 Cennini, Il libro dell'arte/Ed. Frezzato (2008), 129.

28 Cennini, Il libro dell'arte/Übers. Ilg (1888), 59 (mit Veränderungen). 
Für Panofsky bildete die in diesem wie auch in Kap. 28 zum Ausdruck gebrachte Einstellung zur Natur eine Kernaussage des Malereiverständnisses Cenninis, die ihn mit der »theoretischen und historischen Kunstschriftstellerei der italienischen Renaissance« verband:

Es mag dem modernen Leser einigermaßen sonderbar anmuten, wenn der - im übrigen noch tief in mittelalterlicher Werkstattüberlieferung wurzelnde - Traktat des Cennino Cennini dem Künstler, der eine Gebirgslandschaft darstellen will, den wohlgemeinten Rat erteilt, sich Felssteine zu nehmen und sie in geziemender Größe und Beleuchtung abzumalen, - und doch bezeichnet diese Vorschrift den Anbruch einer neuen Kunstepoche. Es ist etwas durchaus Neues, wenn dem Maler angeraten wird, sich einem (wenn auch im vorliegenden Falle noch so merkwürdig gewählten) Modell gegenüberzustellen, wenn die Kunstheorie die der Antike anfangs selbstverständliche, vom Neoplatonismus ausgerottete und für das mittelalterliche Denken kaum mehr in Betracht kommende Vorstellung, dass das Kunstwerk eine modellgetreue Wiedergabe des Wirklichen sei, der tausendjährigen Vergessenheit entreißt, und nicht nur der Vergessenheit entreißt, sondern mit vollem Bewusstsein zum Programm erhebt. ${ }^{29}$

Es war Panofsky keineswegs entgangen, dass Cennini dem Künstler auch das Vermögen zubilligte, »sich abwandelnd und erfindend von der Wirklichkeit zu emanzipieren«, aber er verstand Cenninis Äußerungen zur Phantasie nicht als alleinigen Ansatz- und Angelpunkt seiner Kunstanschauung. ${ }^{30}$ Der Frage, ob, und wenn ja, wie Cennini Erfindungsfreiheit und Naturstudium in Einklang bringt, ist er nicht weiter nachgegangen. Sie betrifft direkt die Zuständigkeitsbereiche bzw. das Zusammenspiel von Phantasie und Verstand. Die neue Auffassung der modellgetreuen Naturnachahmung, die nicht länger nur berücksichtigt, »wie die Natur schafft «, sondern auch »was die Natur schafft ${ }^{31}$ impliziert die ihr entsprechende »Forderung nach einer formalen und objektiven Richtigkeit $",{ }^{32}$ und die Erfüllung dieser Forderung ist eine Angelegenheit des Verstandes. Für Cennini stand das außer Frage. Das zeigt bereits Kap. 88. In ihm ist nicht die Phantasie (fantasia), sondern der Verstand (la ragione) die Instanz, die Wirklichkeitsnähe und -illusion ermöglicht: Es wird ausgesagt, dass man Berge mit natürlichem Erscheinungsbild generieren kann (»montagnie [...] cche paino naturali«), indem man sich eine Darstellungsmanier aneignet (»pigliare buona maniera «), die auf der vom Verstand so gut wie möglich gelenkten, zeichnerischen Nachahmung der Licht-Schatten-Verhältnisse natürlicher Modelle basiert. Bereits zuvor, in Kap. 85 , wird die Kolorierung von Bergen als ebenfalls verstandesgemäßes Verfahren beschrieben. ${ }^{33}$

\footnotetext{
29 Panofsky (1975), 23.

30 Panofsky (1975), 31.

31 Panofsky (1975), 22.

32 Panofsky (1975), 24.

33 Cennini, Il libro dell'arte/Ed. Frezzato (2008), 126: „Capitolo LXXXV Del modo del colorire una montagnia, in frescho o in seccho. Su vuoi fare montagnie in frescho e in seccho, fa' un coloro verdaccio, di negro una parte, d'ocria le due parti. Digrada i colori, in frescho di biancho senza tempera, e in seccho con biancha e con tempera, et da' lor quella ragione che dai a una
} 
Cennini rechnet bei der modellgetreuen künstlerischen Nachgestaltung der Erscheinungsformen von Naturdingen mit zwei Faktoren: Phantasie und Verstand, wobei zunächst nicht deutlich zu erkennen ist, wie er sich deren $\mathrm{Zu}$ ständigkeitsbereiche vorstellt. Hierauf wird noch zurückzukommen sein.

\section{Schatten und Bild}

Die Formulierung cose non vedute cacciandosi sotto ombra di naturali bedarf der Erläuterung, und zwar unabhängig davon, ob man sie wörtlich übersetzt (»nicht gesehene Dinge, die sich unter dem Schatten naturhafter Art verbergen «) oder wie Ilg - annimmt, sie bringe bereits den zweiten Schritt malerischen Schaffens zum Ausdruck: die Wiederverwendung der gefundenen Formen (trovare) zur Darstellung erfundener (neu zusammengefügter) Dinge »unter dem Schatten der natürlichen« (comporre e legare insieme). Worin besteht die Analogie von Bild und Schatten? Der Schlagschatten als ein »natürliches Bild« eines Körpers ist nicht gemeint. Im Libro dell 'arte ist nirgends von Schlagschatten die Rede, und zudem können sich cose non vedute nicht unter Schlagschatten verbergen. Auf die von Plinius überlieferte Entstehungsgeschichte der Malerei wollte Cennini daher wohl kaum hinweisen. ${ }^{34}$ Die im Libro an mehreren Stellen erörterten zeichnerischen und malerischen Verfahren des Schattierens (adumbare) lassen sich ebenfalls nicht als ein Verbergen nicht gesehener Dinge verstehen. Die ihnen zugewiesene Funktion besteht darin, in Umrissen erfassten Gegenständen die Erscheinungsform dreidimensionaler Körper zu verleihen. ${ }^{35}$ Schattierungen zeigen zwar etwas, das bei gemalten Figuren in Wirklichkeit nicht vorhanden ist - sie fingieren Körperrelief (riliveo di figure) -, aber selbst das wird nicht explizit thematisiert, ${ }^{36}$ und ebensowenig wird ihnen an irgendeiner Stelle zugleich die Funktion zugewiesen, Dinge zu verbergen. ${ }^{37}$

Mit den in Kap. 1 erwähnten »Schatten natürlicher Dinge, unter denen sich nicht gesehene Dinge verbergen « scheint Cennini auf Schattenvorstellungen philosophischer Provenienz zu rekurrieren, die für sein Verständnis von Malerei von Bedeutung waren. ${ }^{38} \mathrm{Da}$ er das nur an dieser Stelle und zudem in aller Kürze sowie ohne klare begriffliche Distinktionen zum Ausdruck bringt, bleibt fraglich, in

fighura di schuro o di rilievo. E quando ài a ffare le montagnie che paiano più a lungi, più fa' scuri i tuoi colori; et quando le fai dimostrare più a apresso, fa' i colori più chiari.«

34 Kruse (2003), 75 sowie Kruse (2010), 290-291 möchte dennoch eine Verbindung zu Plinius sehen; skeptisch auch Löhr (2008b), 172, Anm. 104.

35 Zum Begriff rilievo vgl. Feser (2010), 276-278.

$36 \mathrm{Zu}$ beachten ist in diesem Zusammenhang Frezzatos Emendation, derzufolge die Aufgabe der Malerei nicht darin besteht zu zeigen, »dass das, was nicht ist, sei« (che non $\grave{e}$, sia), sondern dass sie zeigt, »was nicht ist« (quello che nonne sia). Cennini, Il libro dell'arte/Ed. Frezzato (2008), 62 u. Anm. 1.

37 Pardo (1997), 44, meint dagegen von einem »adumbrare mentali concetti« sprechen zu können. Vgl. auch Löhr (2008b), 171-176, bes. 171 und Stoichita (1997), 48-67, 89.

38 Vgl. Kemp (1997), 131. 
welchem Umfang er über den in der Tradition der platonischen Ideenlehre stehenden philosophischen Gehalt dieser Vorstellungen informiert war. Dass es sich um gängiges platonisches Erbe handelt, steht außer Frage. Gelehrten und philosophisch gebildeten Laien war die Vorstellung geläufig, dass die Malerei »die Schatten der Dinge« (d.h. ihre natürlichen Erscheinungsformen) im Medium der Malerei reproduziert. ${ }^{39}$ Sie kannten und äußerten freilich auch die mit ihr einher gehenden kritischen Vorbehalte gegenüber malerischer Naturnachahmung als einem nach dem Kriterium der Wahrheit minderwertigen Nachäffen der Natur bzw. der von ihr generierten Erscheinungen (Schatten). ${ }^{40}$ Aber es gab auch eine positive Sicht auf die »Schatten der Dinge«, mit der sich die Malerei in ein positiveres Licht rücken ließ. Sie basierte auf der für neuplatonisch und aristotelisch geprägte Theologen und Philosophen gleichermaßen fundamentalen Annahme, derzufolge die Natur als »Werkzeug einer fortwährenden Verwandlung der ideae oder exemplaria des göttlichen Verstandes in die kreatürliche Welt« fungiert, ${ }^{41}$

39 Alanus ab Insulis, Anticlaudianus I, vv. 122-125/Ed. Bossuat (1955), 60: [...] hic hominum mores picturae gracia scribit: / sic operi proprio pictura fideliter heret, / ut res picta minus a vero deviet esse. Io nova picture miracula! transit ad esse / quod nihil esse potest! picturaque simia veri, / arte nova ludens, in res umbracula rerum / vertit, et in verum mendacia singula mutat. Der Passus zeigt, dass Alanus ab Insulis mit der Vorstellung vertraut ist, die Malerei äffe nur die Schatten (= natürlichen Erscheinungsformen) der Dinge nach. Bei den beschriebenen Gemälden des Palast der Natura handelt es sich jedoch nicht um von Menschenhand gemalte Bilder. Sie sind ebensowenig real wie der aus Gold, Silber und Edelsteinen errichtete Palast. Die in von der übermenschlichen Malerei in »Dinge« verwandelten »Schatten der Dinge« weichen daher nicht vom »wahren Sein« ab. Erfahrungen mit zeitgenössischer Malerei hat Alanus nicht thematisiert. Dieser Sachverhalt wurde vielfach nicht berücksichtigt, was zu problematischen Deutungen führte: Flasch (1965), 296: »Alanus ab Insulis (hat) das Schöpfertum des Künstlers wirklich gesehen und als ,Wunder erfahren, aber nicht ohne den Verdacht, es sei doch Gaukelwerk, was da entstehe«; Summers (1981), 46: »Alanus ab Insulis (stresses) the potential for paradox in the illusions of painting«; Eco (1991), 161: "Zweifellos sagen die mittelalterlichen Autoren, wenn sie sporadisch über bildende Kunst nachdenken, die Dinge, die in den Systemen keinen Platz haben. Alanus ab Insulis ergeht sich [...] in Bewunderungsäußerungen wie der folgenden [...] . Arnulf (2004), 414: »Dieser Abschnitt stellt im Grunde einen Exkurs über die Macht der Malerei dar." Arnulf (2008), 147: »ein Diskurs über die Fähigkeiten der Malerei die Natur nachzuäffen, aber auch Erlogenes - gemeint sind antike Götter - wahr erscheinen zu lassen.« Vgl. auch Kruse (2000), 309; Kruse (2003), 77-78 und Kruse (2001), 137: »(Alanus) führt aus dem platonischen Dilemma und wird zum Garant einer neuen Malerei.« Vgl. dagegen Kobusch (2011), 145: „Schon die Beschreibung des Hauses der Natura atmet den Geist Platos. Hier ist der Unterschied zwischen dem defizienten Sein eines Abbildes und dem wahren Sein des Urbildes aufgehoben. Die Gemälde und Bilder der Dinge, die sonst nur Träume des Wahren sind, - hier sind an den Wänden im Haus der Natura sind sie das Wahre selbst. Die göttliche Kunst, die die Schatten der Dinge selber zu Dingen macht, zeigt die Grenzen der aristotelischen Logik auf $(I, 214)$. Gerade von der Ontologie des Bildes her ist Plato der nächste Geistesverwandte: ‘doch göttlicher träumt Plato mit tiefem Geist der Welt und des Himmels Geheimnis / und versucht den Sinn der Gottheit selbst zu erforschen< (I, 133).«

40 Vgl. Bautier (1988), 85-86 mit Belegen für die negative Bedeutung von Phantasiebildern als umbrae. Zum Topos ars simia naturae siehe Panofsky (1975), 21, Anm. 88 und 24, Anm. 95; Janson (1952); Curtius (1978), 522-523; Kris/Kurz (1980), 116; Ginzburg (2006).

41 Kablitz (1998), 312. 
und allen natürlichen Dingen eine Ähnlichkeit mit ihrem Schöpfer eingeschrieben ist, die zur Erkenntnis der göttlichen Schöpfung hinführen kann. So vertrat Bonaventura 1259 in seinem Itinerarium mentis in Deum die Auffassung, dass alle natürlichen Dinge und Geschöpfe Schatten, Widerhall und Gemälde der Ideen des Geistes Gottes sind, mittels derer die »sinnenbefangene Seele« durch »Sinnliches, das sie sieht, hindurchgeführt werde zum Geistigen, das sie nicht sieht. ${ }^{42}$ Vor dem Hintergrund christlich-neuplatonischen Gedankenguts und seiner Bild- und Schattenmetaphorik gesehen sind die Schatten, von denen Cennini in Kap. 1 spricht, eine Metapher für körperliche Erscheinungsformen, und mit den cose non vedute wären demzufolge die ihnen zugrunde liegenden und in ihrer irdischen Hülle nicht (bzw. nicht deutlich) sichtbaren Urbilder, die göttlichen Ideen, gemeint. Mit seinem Rekurs auf die »nicht gesehenen Dinge « bringt Cennini zum Ausdruck, dass die Formen, die der Maler zeichnet, nicht rein manuell hervorgebracht werden: Das trovare cose non vedute fordert Intellekt und Phantasie. Durch sie vermag der Maler annäherungsweise, d.h. seinem Wissen und seinen Fähigkeiten gemäß, »Dinge«, d.h. begrifflich von ihm nicht näher bestimmte metaphysische Wahrheiten, ${ }^{43}$ zu zeigen, die in der sichtbaren Wirklichkeit der Naturdinge nicht vorhanden sind. Die aus der sinnlichen Wahrnehmung körperli-

42 Bonaventura, Itinerarium mentis in deum II,11/Ed. Kaup (1961), 88-90: [...] colligere possumus quod omnes creaturae istius sensibilis mundi animum contemplantis et sapientis ducunt in Deum aeternum, pro eo quod illius primi principii potentissimi, sapientissimi et optimi, illius aeternae originis, lucis et plenitudinis, illius, inquam artis efficientis, exemplantis et ordinantis sunt umbrae, resonantiae et picturae, sunt vestigia, simulacra et spectacula nobis ad contuendum Deum proposita et signa divinitus data; quae, inquam, sunt exemplaria vel potius exemplata, proposita mentibus adhuc rudibus et sensibilibus, ut per sensibilia, quae vident, transferantur ad intelligibilia, quae non vident, tanquam per signa ad signata. „Daraus können wir entnehmen, dass alle Geschöpfe dieser sinnenfälligen Welt die Seele des Betrachtenden und Weisen zum ewigen Gott hinführen, weil sie von diesem ersten, mächtigsten, weisesten und besten Prinzip, von diesem ewigen Ursprung, ewigen Licht, von dieser ewigen Fülle, von dieser, sage ich, schaffenden, abbildenden, ordnenden Kunst Schatten sind, Echo und Gemälde; Spuren sind sie, Statuen und Schaustücke, die uns vorgeführt werden, um Gott zu schauen, und Zeichen, die uns von Gott gegeben sind; ich möchte sagen, sie sind Abbilder oder besser Abgebildetes, vorgeführt einer noch ungebildeten oder sinnenbefangenen Seele, damit diese durch Sinnliches, das sie sieht, hindurchgeführt werde zum Geistigen, das sie nicht sieht, wie durch Zeichen zum Bezeichneten.« Vgl. hierzu Flasch (1965), 295 und für eine kurze Darstellung der Erkenntislehre des Bonaventura, Kobusch (2011), 265-272. Zu Bonaventuras bildtheoretischen Auffassungen siehe auch Ruth Wolff: »Das kreative Bild. Zur paradigmatischen Rolle des Siegels im Bilddiskurs Bonaventuras mit einem Vergleich zu Thomas von Aquin« (in Vorbereitung). Ich danke der Verfasserin für die Möglichkeit der Lektüre des Manuskripts.

43 Da Cennini im ersten Kapitel zwischen trovare cose und comporre (cose) unterscheidet, ist es meines Erachtens unwahrscheinlich, dass er mit den unter den Schatten sich verbergenden Dingen nicht nur metaphysische Wahrheiten der göttlichen Schöpfung, sondern zugleich auch Erfindungen des Malers meinte. Anderer Auffassung sind u.a. Summers (1981), 493, Anm. 90; Pardo (1997), 44; Wolf (2002), 237 und zuletzt auch Löhr (2008b), 171: »Die Dinge, die sich im Schatten verbergen, die abstrakten concetti profaner Ausstattungsaufträge genauso wie die vom Intellekt erkannten metaphysischen Wahrheiten, in deren Dienst die religiöse Kunst steht, werden durch Züge des Zeichners fixiert (fermare) und gelangen wiederum durch den Schatten zur Anschauung.« 
cher Dinge hervorgegangenen mentalen Vorstellungen wurden in der mittelalterlichen Fakultätenpsychologie häufig als Bilder (picturae, species) oder in Anlehnung an die platonische Schattenmetaphorik ebenfalls als Schatten bezeichnet: als unkörperliche Bildschatten der körperlichen Dinge der irdischen Welt. ${ }^{44}$ Dante, der in der Divina Commedia vorgibt, jenseitige Wirklichkeit sinnlich wahrgenommen zu haben, bezeichnet daher in Par. 1,23 das, was ihm als Erinnerungsbild in seinem Kopf von seiner Jenseitsreise blieb, explizit als Schattenbild (ombra del beato regno). ${ }^{45}$ Die Divina Commedia ist das prominenteste Zeugnis dafür, dass die platonische Schattenmetaphorik nicht nur in theologischen und philosophischen Traktaten tradiert wurde. Ein weiteres Beispiel findet man in Purgatorio 12,61-69 in Verbindung mit der Beschreibung eines das zerstörte Troja darstellenden skulpturalen Reliefbilds. Es ist das letzte der Bodenreliefs, die Exempla der Superbia darstellen, die ebenso wie die Demuts-Reliefs in Anlehnung an den im Mittelalter geläufigen Topos deus artifex ${ }^{46}$ als Zeugnisse einer »jenseitigen Kunst» präsentiert werden:

Vedea Troia in cenere e in caverne:

o Ilìòn, come te basso e vile mostrava il segno che li si discerne! Qual di pennel fu maestro o di stile che ritrasse l'ombre e' tratti ch' ivi mirar farieno uno ingegno sottile? Morti li morti e $i$ vivi parean vivi: non vide mei di me chi vide il vero, quant' io calcai, fin che chinato givi.

Und ich sah Troja in Schutt und Asche. O Ilion, wie sahst du doch heruntergekommen aus auf der Zeichnung, die dort zu erkennen ist!

Welcher Meister des Pinsels oder des Stifts hätte so die Formen [wörtl. Schatten, PS] und die Linien darzustellen vermocht, die dort selbst den feinsten Kunstverstand zum Erstaunen brächten!

44 Hugo von St. Victor: De unione corporis et spiritus, PL 177, 1854, Sp. 287d: Rationalis autem substantia incorporea lux est; imaginatio vero, inquantum corporis imago est, umbra est. Et idcirco postquam imaginatio usque ad rationem ascendit, quasi umbra in lucem veniens, et luci superveniens, inquantum ad eam venit, manifestatur, et circumscribitur; inquantum illi supervenit, obmubilat eam, et obumbrat, et insolvit, et contigit. »Die rationale Substanz ist das körperlose Licht, die Vorstellung aber, insofern sie Abbild des Körpers ist, der Schatten. Und demnach steigt die Vorstellung bis zur Vernunft auf, als ob der Schatten zum Licht kommt und über es kommt, sofern er zu ihm kommt, wird er sichtbar und klar umrissen, sofern er über es kommt, bewölkt und verschattet er es, löst es auf und befleckt es.« Vgl. hierzu Hamesse (1988), 168170.

45 Vgl. hierzu Regn (2009), 375, der zwar annimt, dass hier in erster Linie ein "Vorstellungsmuster« der integumentalen Poetik aufgegriffen wird, aber gleichwohl hervorhebt, dass Dante den »Gegensatz zwischen Wahrheit und Erfindung [...] verwischt«. Vgl. Curtius (1978), 527-529; Kris/Kurz (1980), 64-86, bes. 78-86. 
Tot schienen die Toten und lebend die Lebendigen. Auch wenn es wirklich gewesen wäre: Besser hätte es niemand sehen können, all das, worauf ich mit gebeugtem Kopf den Fuß setzte. ${ }^{47}$

Zwischen bildlicher Darstellung und dargestellter Wirklichkeit wird explizit unterschieden: das Bild wird als segno ausgewiesen. ${ }^{48}$ Der Täuschungseffekt bildlicher Illusion steht thematisch nicht im Zentrum. ${ }^{49}$ Die Bewunderung der übernatürlichen Kunst richtet sich (zunächst vordergründig) auf die Genauigkeit, mit der im zeichnerischen Entwurf »Tote « und »Lebendige « erfasst und deutlich unterschieden wurden. Es ist nicht von Hammer und Meißel, sondern von Pinsel und Stift die Rede, d.h. das Erstaunliche wird nicht der auf unkörperliche Schattengebung nicht angewiesenen Bildhauerarbeit, sondern dem zeichnerischen Entwurf zugeschrieben, und indem dieser als Produkt des Nachzeichnens von Schatten und Zügen beschrieben wird, ist das Bild zugleich als Medium der Sichtbarmachung göttlicher Ideen ausgewiesen. Die geistige Bildschärfe der göttlichen Kunst erlaubt es dem Betrachter zudem, mehr als die historische Wirklichkeit der Zerstörung Trojas zu erkennen. Der auf das gesamte Bild als Zeichen sich beziehende Vers »non vide mei di me chi vide il vero« ist doppeldeutig. Das TrojaReliefbild ist nicht nur ein perfekter Ersatz für Augenzeugenschaft, es offenbart zugleich die moralische Wahrheit des dargestellten Ereignisses: die Erkenntnis, dass Hochmut die Trojaner ins Verderben führte. Dass moralische Belehrung auf dem Weg zum Paradies der Zweck dieses wie auch der zuvor beschriebenen Reliefs ist, wird in der folgenden Aufforderung Vergils ironisch zum Ausdruck gebracht (Purg. 12, 70-72):

Or superbite, e via col viso altero,

figliuoli d'Eva, e non chinate il volto

si che veggiate il vostro mal sentero!

$\mathrm{Ja}$, bildet euch nur recht viel ein, macht weiter mit der stolzen Miene, ihr Kinder Evas, und nur nicht nach unten geschaut, ihr könntet ja erkennen, auf was für Abwegen ihr seid! $!^{50}$

Francesco di Bartolo da Buti hat in seinem Kommentar zur Divina Commedia die poetische Hintergründigkeit der Reliefbeschreibung Dantes nicht erfasst. Er verstand das Relief nicht als dichterische Fiktion einer die Vollkommenheit des deus artifex demonstrierenden jenseitigen Kunst, sondern erläuterte Dantes Verse ohne höhere semantische Erwartungen lediglich mit Standardwissen. Gemäß der mittelalterlichen Fakultätenpsychologie interpretierte er die Schatten als in die Skulpturen übertragene mentale Schatten (Vorstellungen) ihres Urhebers und bewertete ihren Erkenntniswert lediglich nach den Maßstäben menschlicher Kunst und Naturnachahmung. Bewunderungswürdige Kunstfertigkeit zeigt sich

47 Übers. Köhler (2011), 237.

48 Vgl. hierzu Kablitz (1998), 348-349; Picone (2006), 98-99.

49 Vgl. dagegen Belting (2001), 202.

50 Übers. Köhler (2011), 239; vgl. zu dieser Stelle Kablitz (1998), 350. 
für ihn nur in der im Reliefbild manifesten Fähigkeit, Dinge ihren Eigenschaften gemäß (modellgetreu) präzise wiederzugeben. ${ }^{51}$ Diese Fähigkeit besäßen nur ingegni sottili und nicht die grossi ingegni. Die Überlegenheit des jenseitigen Bildes, das (durch eine miglior sembianza, Purg. XII, 22) einen ungetrübten, perfekten Zugang zur göttlichen Wahrheit ermöglicht, bleibt unkommentiert. Francesco Buti wird Dantes Versen inhaltlich nicht gerecht, aber seine Ausführungen sind gleichwohl als volkssprachliches Zeugnis für rudimentäre Kenntnisse der (neu)platonischen Schattenmetaphorik bzw. der mittelalterlichen Fakultätenpsychologie beachtenswert.

Die in Cenninis Libro enthaltenen Ausführungen sind weniger klar und weisen zugleich noch stärkere Vereinfachungen auf als diejenigen Butis. Insbesondere sind seine Angaben zu semantischen Aspekten bildlicher Darstellung natürlicher Einzeldinge noch dürftiger. Seine unmittelbaren Quellen bleiben im Dunkeln. Dante und seine Kommentatoren rechtfertigen es, dem Wissensfundus der volkssprachlichen Dichtung und der Laienbildung Relevanz zuzuschreiben. Aber gebildete Geistliche (Franziskaner ${ }^{52}$ ) könnten als mündliche Vermittlungsinstanz ebenso im Spiel gewesen sein. Begriffliche Indizien sind rar, da Cennini einschlägige philosophische Fachtermini (similitudo, forma, materia, idea usw.) nicht verwendet. Aber man findet an zwei Stellen Anhaltspunkte dafür, dass mit trovare cose non vedute das über die sinnliche Wahrnehmung hinausgehende Erkennen der natürlichen Dinge durch den Verstand gemeint ist: Die erste Stelle befindet sich in Kap. 30. Es handelt sich um die einzige Formulierung, in der im Libro dell'arte der Begriff verità explizit zur Bestimmung der Darstellungsaufgabe verwendet wird. Cennini erörtert, wie man die Maße einer Figur präzise zeichnerisch erfasst: »conviene che con intelletto ti ghuidi; e troverai la verità, ghuidandotì per questo modo. ${ }^{53}$ Zeichnerische Formfindung wird hier mit Wahrheitsfindung gleichgesetzt. Den zweiten Anhaltspunkt liefert der in der Rubrik des Kap. 23 verwendete Begriff sustanza: »In che modo poi 〉torrer la sustanza

51 Buti, Commento/ND (1989), 285: „Dice dunque così il testo: ,Vedeac; io Dante scolpita ne los spasso de la prima cornice, >Troia< [...] >di pennel fu maestro〈; cioè fino dipintore, o >di stile〈; cioè o disegnatore con stilo ne le tau[o]le, , Che‘, cioè lo quale, ,ritrasse<; cioè cavasse da quella scolpitura; e nota che propriamente si dice sritraereর: imperò che l'apprensiva apprende, e poi che àe appreso l'obietto, ricava di dentro da sè, e produce fuora l'appresso, ll'ombre<; cioè l'ombrature che erano in quelle scolpiture, `e li atti<; cioè scolpiti in quello marmo; e pero dice: >quivi<; cioè ch'erano in quello luogo, `Mirar<; cioè meravilliarsi, ,farebbe‘; non ogni grosso dipintore e disegnatore, che di ciò pogo s'intenderebbe; ma lo fine dipintore e disegnatore: imperò che ritrarrebbe propriamente come stanno, >ogni ingegno sottile`? L'ingegni sottili sono quelli che cognosceno le proprie dipinture e disegnature, e non li grossi ingegni; e però si meravillierebbeno de la sottilliezza dell'arteficio.« Vgl. Löhr (2008b), 157.

52 Vgl. hierzu Seiler (2012).

53 Cennini, Il libro dell'arte/Ed. Frezzato (2008), 83. Zu beachten ist in diesem Zusammenhang auch die in Kap. 5 (65) enthaltene Aufforderung: »ti conviene avere l'ordine di potere incominciare a disegniare il più verit[e]vile.« Das Wort verità kommt in Kap. 161 nochmals vor (181), allerdings lediglich in einer Formulierung, die das Zutreffen einer Aussage unterstreicht: »Elli è verità che di tutti colori che adoperi in tavola poi adoperare in carta; ma voglionsi macinare sottilissimamente.« 
d'una buona fighura o designio con carta lucida«. Als substantia wurde in philosophischen Diskursen das dem menschlichen Intellekt zwar grundsätzlich als gegeben vorstellbare, aber nicht direkt, sondern nur mittels der Vorstellungsbilder der Phantasie partiell erfassbare unveränderliche Wesen eines (natürlichen) Dings verstanden. ${ }^{54}$ In diesem Sinne kommt der Begriff auch in Dantes Convivio $(3,4,9-$ 10) vor. Der Passus ist zugleich aufschlussreich für das (von Cennini an keiner Stelle seines Libro erläuterte) Zusammenspiel von Phantasie und Intellekt:

(9) Tornando adunque al proposito, dico che nostro intelletto, per difetto da la virtì de la quale trae quello ch'el vede, che è virtù organica, cioè la fantasia, non puote a certe cose salire (però che la fantasia nol puote aiutare, ché non ha lo di che), sì come sono le sustanze partite da materia; de le quali se alcuna considerazione [san$z a]$ di quella avere potemo, intendere non le potemo né comprendere perfettamente. (10) Ed di ciò non è l'uomo da biasimare, ché non esso, dico, fue di questo difetto fattore, anzi fece ciò la natura universale, cioè Iddio, che volse in questa vita privare noi da questa luce; che, perché elli lo si facesse, presuntuoso sarebbe ragionare. (11) Si che, se la mia considerazione mi transportava in parte dove la fantasia veniva meno a lo'ntelletto, se io non poteva intendere non sono da biasimare. Ancora, è posto fine al nostro ingegno, a ciascuna sua operazione, non da noi ma da l'universale natura; $e$ però è da sapere che più ampi sono le termini de lo 'ngegno [a pensare] che a parlare, e più ampi a parlare che ad accennare. (12) Dunque se 'l pensiero nostro, non solamente quello che a perfetto intelletto non viene ma eziandio quello che a perfetto intelletto si termina, è vincente del parlare, non semo noi da biasimare, però che non semo di ciò fattori.

(9) Zum Vorliegenden zurückkehrend, sage ich, dass unser Intellekt aufgrund des Mangels der Kraft, von der er das nimmt, was er sieht, die eine organische Kraft ist, nämlich die Phantasie, zu gewissen Dingen, wie es die von der Materie getrennten Substanzen sind, nicht hinaufsteigen kann, denn die Phantasie kann ihm nicht helfen, denn sie hat die Mittel nicht; auch wenn wir von diesen [Substanzen] ohne diese [Phantasie] irgendeine Vorstellung haben können, so können wir sie doch weder vollständig verstehen noch begreifen. (10) Und diesbezüglich ist der Mensch nicht zu tadeln, denn nicht er, sage ich, war der Gestalter dieses Mangels, sondern die allgemeine Natur, d.h. Gott, hat dies gemacht, der uns in diesem Leben dieses Lichtes berauben wollte; weswegen er dies so gemacht hat, zu ergründen wäre anmaßend. (11) Wenn meine Überlegung mich in eine Region geführt hat, wo die Phantasie dem Intellekt kaum beistand, so bin ich nicht zu tadeln, wenn ich nicht verstehen konnte. Weiter ist unserer Fähigkeit [und] jeder ihrer Handlungen eine Grenze gesetzt, nicht von uns, sondern von der allgemeinen Natur; und hierzu ist zu wissen, dass die Grenzen der Fähigkeit des Denkens weiter sind, als jene des Sprechens und jene des Sprechens weiter sind, als jene des Zeigens.

54 Bormann/Franzen/Krapiec/Oening-Hanhoff, Art. "Form und Materie/Stoff«, Historisches Wörterbuch der Philosophie, Bd. 2, Sp. 977-1030; Halfwassen/Wald, Art. »Substanz/ Akzidens«, Bd. 10, Sp. 495-553, v.a. Sp. 495-521 (I. Antike, J. Halfwassen; II. Mittelalter, B. Wald); Hoffmann, Art. »Wesen«, Bd. 12, Sp. 621-649, bes. Sp. 622-634 (I. Antike, Red.; II. Mittelalter, T. Hoffmann). 
(12) Wenn also unser Denken nicht nur das, das nicht zum vollkommenen Intellekt gelangt, sondern auch das, das im vollkommenen Intellekt zu seinem Ende kommt, das Sprechen übertrifft, so sind nicht wir zu tadeln, denn nicht wir sind dessen Gestalter. $^{55}$

Cennini lässt unerwähnt, dass der Intellekt Beistand von der Phantasie erhält, und er äußert sich auch nicht zu den Grenzen »des Zeigens" (accennare) oder zum Umfang dieses Vermögens im Vergleich zum »Sprechen « (parlare). Da es in Kap. 23 des Libro dell'arte vorrangig um die Beschreibung der Technik des Kopierens mit Hilfe von Transparentpapier (carta lucida) geht, gibt er nur einen beiläufigen Hinweis auf das, was er bereits in Kap. 1 als wesentlichen Grundzug der Malerei thematisierte: das Vermögen, zeigen zu können, was nicht (sichtbar) ist (»dimostrare quello che nonne sia«). Er war überzeugt, dass der vom Verstand angeleitete und mit jahrelang geschulter Hand präzise ausgeführte disegno einem zumindest partiellen Erfassen der sustanza gleichkam. Die Rede ist von einer "guten Figur« eines fertig ausgeführten Gemäldes, deren die Naturwahrheit somit "gut « festhaltenden disegno es mit feinem Stift möglichst präzise kopierend zu erfassen gilt. Dabei betont Cennini, dass es darauf ankomme, Schattenpartien, also Partien mit wenig prägnanten Linien, abstrahierend nachzuzeichnen (»cchosi gieneralmente tocchando alchune ombre, sì chome a tte è possibile potere vedere e fare «) ${ }^{56}$ Das Kopieren mit dem technischen Hilfsmittel der carta lucida war für ihn eine den Intellekt involvierende Tätigkeit. Er schildert das Erfassen der Form nicht als simples mechanisches Faksimilieren, das nur einen sinnlichen Sehvorgang erfordert, sondern als einen Vorgang abstrahierender Formfindung, bei dem nur mit Hilfe des Intellekts ein substanzieller Wahrheitsbezug hervorgebracht werden kann. $^{57}$

\section{Begabung und Streben nach Wissen: $»$ Lo'nteletto al disegno si diletta solo [...]«}

Dante lässt keinen Zweifel daran, dass Höchstgrade zeichnerischer Präzision ein ingegno sottile voraussetzen. Francesco Buti bekräftigte dies, indem er ausdrücklich feststellte, dass diese Fähigkeit nicht allen Menschen gegeben sei. Cennini hielt ebenso eine besondere Begabung für notwendig. Es ist hier auf das Kap. 2 hinzuweisen, in dem Cennini darlegt, wer seiner Auffassung nach am besten geeignet ist, Vollkommenheit in der Malerei zu erreichen. Neben den Kategorien animo gientile und amor naturale stehen Intellekt und das durch einen Meister

55 Dante, Das Gastmahl, Drittes Buch/Ed. Ricklin/Chevenal (1998), 29.

56 Cennini, Il libro dell'arte/Ed. Frezzato (2008), 77-78.

57 Das Bemühen um das genaue Erfassen der Substanz einer Figur richtet sich auf die Umrisse der Vorlage (»i contorni e $\cdot$ lle stremità del disegno«); Schattierungen können nach der Wegnahme der "carta lucida" nach eigenem Belieben ergänzt werden (»e llevando poi la carta, poi tocchare d'alchuni bianchetti et rilievi sì chome tu ài i piaceri su«). 
vermittelte Wissen im Vordergrund. Von Phantasie ist in diesem Zusammenhang nicht die Rede, was erneut zeigt, dass diese nicht den alleinigen Angelpunkt seiner theoretischen Gedanken bildet. Sie ist wichtig, aber sie ist nicht die entscheidende Instanz.

Capitolo II Come alchuni vegnono all'arte, chi per animo gientile e chi per guardagnio.

Non sanza cagione d'animo gientile, alchuni si muovono di venire a quest'arte, piacciendoli per amore naturale. Lo 'nteletto al disegno si diletta solo, ché da lloro medesimi la natura a cciò gli trae, sanza nulla ghuida di maestro, per gientileza d'animo, e per questa dilettarsi. Seguitano a volere trovare maestro, e con questo si disponghono chon amore d'ubidenza, stando in servitù per venire a perfezion di ciò. Alchuni sono che per povertà e necessità del vivere seguitano, sì per guadagno e anche per l'amor dell'arte; ma sopra 'ttutti, quelli da 'cchommendare è quelli che per amore e per gentileza all'arte predetta venghono. ${ }^{58}$

Kap. II Wie einige zur Kunst gelangen, welche aus edler Gesinnung und welche des Gewinnes halber.

Nicht ohne Anregung eines edlen Sinnes entschließen sich manche zu dieser Kunst zu gehen, indem sie aus natürlicher Liebe daran Gefallen finden. Der Verstand erfreut sich an der Zeichnung allein; aus natürlicher Neigung zu dem, was anzieht; ohne irgendeine Führung durch einen Lehrer, (nur) durch den Adel des Geistes und infolge des Erfreuens durch diesen. Zugleich werden sie danach streben, einen Meister zu suchen. Diesem unterordnen sie sich in Liebe zum Gehorsam, in Untergebenheit stehend, damit sie zur Vollkommenheit darin gelangen. Einige gibt es, welche aus Armut und Not des Lebens ihr folgen, also Gewinnes wegen und auch aus Liebe zur Kunst. Aber es sind über all diese hinaus, die zu rühmen, welche nur aus Liebe und edlem Sinn zu der genannten Kunst streben. ${ }^{59}$

Das Kapitel thematisiert natürliche Begabung und edle Gesinnung als Voraussetzungen für diejenigen, die Vollkommenheit in der Malerei erreichen wollen. Die Begriffe amor naturale und animo gentile lassen Beziehungen zur Dichtungslehre des dolce stil nuovo erkennen. ${ }^{60}$ Im Convivio hat Dante amor naturale und gentilezza erläutert. Sie bilden für ihn Voraussetzungen für die Liebe zur Wahrheit und sind somit für eine philosophische Poesie unerlässlich. Bei Cennini haben diese Begriffe eine vergleichbare Bedeutung. Das zeigt insbesondere der Satz: »Der Verstand erfreut sich an der Zeichnung allein [...] . Mit ihm bringt Cennini zum Ausdruck, dass nicht eine natürliche Vorliebe zu einer handwerklichen Tätigkeit gemeint ist, eine Vorliebe, die ein individuelles Vergnügen fundiert, sondern eine besondere Begabung zu einer hochwertigen epistemischen Kompetenz. Aufgrund des substanziellen Wahrheitsbezugs des disegno ist mit der natürlichen Neigung des Intellekts zu diesem nichts anderes als ein Streben nach Wissen gemeint. So verstanden tritt mit dem Satz die Nähe zu philosophischem Schulwissen ins

58 Cennini, Il libro dell'arte/Ed. Frezzato (2008), 63.

59 Cennini, Il libro dell'arte/Übers. Ilg (1888), 5 (mit einigen Änderungen).

60 Vgl. hierzu Seiler (2012). 
Blickfeld. Dass alle Menschen von Natur aus nach Wissen streben, sagt Aristoteles am Anfang der Metaphysik. Seine Feststellung wurde vielfach kommentiert, wobei vor allem die Ursachen für den begrenzten Erfolg dieses menschlichen Strebens Aufmerksamkeit fanden. So auch bei Dante am Anfang des Convivio $(1,1,1-5)$ :

(1) Sí come dice lo Filosofo nel principio de la Prima Filosofia, tutti li uomini naturalmente desiderano di sapere. La ragione di che puote essere ed è che ciascuna cosa, da providenza di prima natura impinta, è inclinabile a la sua propria perfezione; onde, acciò che la scienza è ultima perfezione de la nostra anima, ne la quale sta la nostra ultima felicitade, tutti naturalmente al suo desiderio semo subietti. (2) Veramente da questa nobilissima perfezione molti sono privati per diverse cagioni, che dentro al'uomo e di fuori da esso lui rimovono da l'abito di scienza. (3) Dentro da l'uomo possono essere due difetti e impedi[men]ti: l'uno da la parte del corpo, l'altro da la parte dell'anima. Da la parte del corpo è quando le parti sono indebitamente disposte, si che nulla ricevere può, si come sono sordi e muti e loro simili. Da la parte de l'anima è quando la malizia vince in essa, sì che si fa seguitatrice di viziose delettazioni, ne le quali riceve tanto inganno che per quelle ogni cosa tiene a vile. (4) Di fuori da l'uomo possono essere similemente due cagioni intese, l'una de le quali è induttrice di necessitade, l'altra di pigrizia. La prima è la cura familiare e civile, la quale convenevolmente a sè tiene de li uomini lo maggior numero, si che in ozio di speculazione esser non possono. L'altra è lo difetto del luogo dove la persona è nata e nutrita, che tal ora sarà da ogni studio non solamente privato, ma da gente studiosa lontano. (5) Le due di queste cagioni, cioè la prima da la parte [di dentro e la prima da la parte] di fuori, non sono da vituperare, ma da escusare e di perdono degne; le due altre, avvenga che l'una più, sono degne di biasimo e d'abominazione.

(1) Wie der Philosoph zu Beginn der Metaphysik sagt, wünschen alle Menschen von Natur aus zu wissen. Der Grund hiervon könnte sein und ist, dass jedes Ding, von der Vorsehung der ersten Natur geprägt, zu seiner eigenen Vervollkommnung neigt; weswegen, da die Wissenschaft, in der unser höchstes Glück besteht, die letzte Vervollkommnung unserer Seele ist, wir alle von Natur aus dem Verlangen nach ihr unterworfen sind. (2) In Wahrheit sind viele [Menschen] dieser edelsten Vervollkommnung wegen verschiedener Ursachen, die im Menschen selbst und außerhalb seiner, ihn vom Habitus zur Wissenschaft entfernen, beraubt. (3) Im Innern des Menschen können zwei Mängel und Hindernisse sein: Das eine von seiten des Körpers, das andere von seiten der Seele. Seitens des Körpers [besteht ein Hindernis], wenn die Teile ungenügend veranlagt sind, so dass er nichts empfangen kann, wie es bei Tauben und Stummen und ihnen Ähnlichen der Fall ist. Seitens der Seele [besteht ein Hindernis], wenn die Bosheit in ihr die Oberhand gewinnt, so dass sie sich zur Anhängerin lasterhafter Freuden macht, in denen sie soviel Täuschung erfährt, dass sie dadurch alles für niederträchtig hält. (4) Außerhalb des Menschen können ebenso zwei Ursachen ausgemacht werden, deren eine sich aus Notwendigkeit ergibt, die andere aus Faulheit. Die erste ist die Sorge um die Familie und um die Gemeinschaft, die gebührenderweise die größte Zahl der Menschen an sich fesselt, so dass sie nicht in der Ruhe des Betrachtens leben können. Die andere ist der Mangel des Ortes, an dem die Person geboren und ernährt worden ist, so dass eine solche [Person] jetzt nicht nur jedes Studiums beraubt sein dürfte, sondern auch weit entfernt von gelehrten Leuten. (5) Zwei 
dieser Ursachen, d.h. die erste der (inneren und die erste der) äußeren Seite, sind nicht zu tadeln, sondern zu entschuldigen und der Vergebung würdig; die zwei anderen die eine allerdings mehr, - sind des Tadels und der Verabscheuung würdig. ${ }^{61}$

Cennini fokussiert zwei äußere Hindernisse. Für ihn sind die Sorge um den Lebensunterhalt (povertà e necessità del vivere) sowie ein Mangel an Studium Beeinträchtigungen, die als äußere Ursachen die Ausübung der Malerei als Wissenschaft und die Erreichung von Vollkommenheit negativ beeinflussen. Er stuft diejenigen, die allein aus natürlicher Liebe zur Malerei gelangen als in höherem Maße geeignet ein, aber er sieht ebenso in Entsprechung zu Dantes Ausführungen keinen Anlass, diejenigen zu tadeln, die auch durch äußere Notwendigkeit, des Erwerbs wegen, zur Malerei gelangen. Innere, charakterliche Defizite vernachlässigt Cennini. So sieht er anders als Dante in der Faulheit (pigrizia) keine große Gefahr für die Bereitschaft, die unter Umständen vorhandene räumliche Entfernung zu qualifizierten Lehrern zu überbrücken. Er nimmt an, dass derjenige, der durch amor naturale zur Malerei neigt, auch ein hinreichend starkes Verlangen hat, sich einen Meister zu suchen. Da der Intellekt als entscheidende Triebkraft bei der Neigung zur Malerei im Spiel ist, besitzt das Streben nach Wissen für ihn ein sicheres Fundament. In diesem Zusammenhang wird zugleich deutlich, dass es Cennini fern liegt, natürliche Begabung zur Legitimation von Autodidaktentum heranzuziehen. Der Weg zur perfezione erfordert nach seiner Auffassung Begabung und Wissen. Dabei lässt er keinen Zweifel daran, dass der Gehorsam des angehenden Malers gegenüber dem Meister und seiner Lehre an erster Stelle steht. Im folgenden Kapitel werden weitere Sekundärtugenden gefordert. ${ }^{62}$

Das Wissen, das Cennini auf der »Reise zu dieser Wissenschaft« (der Malerei) ${ }^{63}$ ausbreitet, umfasst vor allem Werkstattrezepte und technische Verfahren. Ein Missverhältnis zwischen dem beanspruchten hohen Rang der Malerei als scienza und den erfassten Wissensbeständen ist unverkennbar. So betont Cennini in Kap. 29, es sei wichtig, dass der Maler sein Leben so führe, »als wenn er Theologie, Philosophie oder andere Wissenschaften zu studieren hätte«, aber er erläutert nur in wenigen Hinweisen, was es inhaltlich konkret bedeutet, dass das Finden und zeichnerische Festhalten der verità eine wissensbasierte Tätigkeit ist. Von »detaillierte(n) Anweisungen für ein Studium nach der Natur ${ }^{64}$ kann nicht die Rede sein. Seine dürftigen Bemerkungen kann man kaum als Grundlage eines »versierten, empirisch ausgerichteten Naturstudiums « charakterisieren. ${ }^{65} \mathrm{Zu}$ Recht wurde darauf hingewiesen, dass sie alles andere als geeignet waren, »um Künstlern die traditionelle, bibelabhängige Sicht auf den menschlichen Körper

61 Dante, Das Gastmahl, Erstes Buch/Ed. Ricklin/Chevenal, (1996), 3-5 und die Kommentierung von Chevenal LI, LX.

62 Vgl. hierzu Seiler (2012).

63 Cennini, Il libro dell'arte/Ed. Frezzato (2008), 80: »il viaggio della detta scienza«.

64 Eusterschulte (2000), 798; die Grenzen von Cenninis Naturstudium vernachlässigt auch Kemp (1997), 133: „Das hinter all diesen Anweisungen stehende übergeordnete Programm ist die wissenschaftliche Deduktion naturalistischer Effekte [...].«

65 Eusterschulte (2000), 800 . 
abzugewöhnen. ${ }^{66}$ Was er in Kap. 30 und Kap.70 über die »richtige« Proportionierung von Figuren mitteilt, basiert auf mittelalterlichem Standardwissen. Selbständige Proportionsstudien und das Zeichnen nach menschlichen Modellen sind nicht vorgesehen. Nur die »vernunftlosen Lebewesen « (animali irrazionali) solle man, da sie »nie irgendein Maß« erkennen lassen, »soweit du kannst « direkt nach dem Naturmodell (del naturale) zeichnen. ${ }^{67}$ Noch dürftiger ist der anatomische Lehrstoff. Der Mann sei um eine Rippe ärmer als die Frau; seinen Penis soll man in der Größe darstellen, »die den Frauen gefällt«, und sein Hodenpaar »klein, von schöner Art und frisch. « Das unablässige Zeichnen nach der Natur (ritrarre sempre del naturale) wird zwar am Ende der zeichnerischen Grundausbildung als zentrale Aufgabe und Weg zum Erfolg (la trionfal porta) beschrieben, es besitzt aber eine geringere Tragweite, als die nachdrücklichen Bemerkungen suggerieren. Die Einbeziehung anderer Wissenschaften - wie sie Ghiberti forderte ${ }^{6}$ - spielt in dem vorrangig materialkundlichen und technikbezogenen Werk keine Rolle. Die in den Lehrgang nicht integrierten, sondern nachträglich angehängten Anleitungen zu Naturabgüssen (Kap. 181-189) waren kaum geeignet, den Mangel an wissenschaftlich fundierten Methoden empirischen Naturstudiums zu kompensieren. Vermutlich handelt es sich um einen Versuch, den steigenden Anforderungen des Naturstudiums Rechnung zu tragen. Der Hinweis auf die Qualität antiker Statuen ist angesichts der gegen Ende des 14. Jahrhunderts in Florenz zunehmenden Verbindungen zwischen Natur- und Antikenstudium nicht erstaunlich.

\section{Das Zusammenspiel von intelletto und fantasia}

Die geistigen Fähigkeiten, die der Maler in hohem Maße mitbringen muss, um zur Erfassung der Naturwahrheit in der Lage zu sein, wurden im Anschluss an die antike Rhetorik mit dem Begriff ingenium bezeichnet. ${ }^{69}$ Der Begriff hatte vor allem bei Humanisten eine neue Konjunktur. In den poetologischen Reflexionen Petrarcas und Boccaccios ist von Phantasie nicht die Rede.$^{70}$ Dass man bei Cennini fantasia statt ingegno vorfindet, hat man daher mit Quintilian, ${ }^{71}$ Philostrat $^{72}$

66 Perrig (1994), 435.

67 Perrig (1994), 429.

68 Ghiberti, I commentarii/Ed. Bartoli (1998), 48: „Ancora bisognia avere conosciuta la disciplina della medicina, et avere veduto notomia, acciò che llo scultore sappi quante ossa sono nel corpo hurnano, volendo comporre la statua virile, e sapere e muscoli sono nel corpo dello huomo e così tutti i nervi e legature sono in esso. Avere peritia de' fatti d'astrologia, della terra; ancora del cielo avere notizia d'esso, i quali i Greci dicono climata, per sito della terra.«

69 Vgl. Kemp (1977), 386-393.

70 Vgl. Kemp (1977), 362.

71 Venturi (1964), 91: $»$ E qui il Cennini si giova forse del passo Quintiliano sulle visioni«; Chastel (1977), 32: »Quintilien - parallèlement à l'usage qu'en fait Dante.« Kruse (2000), 309.

72 Schlosser (1924), 69: »Der Begriff der Phantasie als künstlerischen Agens, eine Erbschaft der ausgehenden Antike, werden wir noch weiterhin bei Cennini wiederfinden.« Einen allgemeinen Hinweis zu den Voraussetzungen der fantasia bei Cennini gibt Grassi (1985), 125: „Concetto 
oder mit Rekurs auf Dante als indirekte »Erbschaft der ausgehenden Antike « zu erklären versucht. ${ }^{73}$ Da die Annahme einer Kenntnis der beiden antiken Autoren mit Cenninis bescheidenem Bildungsniveau nicht zu vereinbaren ist, kommt am ehesten Dante in Frage. Relevant scheinen dessen Auffassungen jedoch nur, soweit sie mit denen der mittelalterlichen Fakultätenpsychologie übereinstimmen. ${ }^{74}$ Das inspirationstheoretische Konzept der alta fantasia (»Poi piovve dentro a l'alta fantasia« - Purg. XVII, 25) ${ }^{75}$ das in der Divina Commedia eine prominente Rolle spielt, findet bei Cennini keine Entsprechung. ${ }^{76}$ Mittelalterliche Erkenntnistheorien schrieben der phantasia (bzw. der imaginatio, sofern beide nicht gegeneinander abgegrenzt wurden) ein zweifaches Vermögen zu: ein reproduktives und ein kreativ-produktives. ${ }^{77}$ In der Hierarchie der Seelenvermögen beschrieb man sie als eine unerlässliche Vermittlungsinstanz zwischen der Sinneswahrnehmung

che non assume qui, ovviamente, significato romantico, ma piuttosto quello premedievale agostiniano-plotiniano [...].«

73 Schlosser (1924), 69; Chastel (1977), 32; Magagnato (1982), XI.

74 Auf die mittelalterliche Fakultätenpsychologie verweist auch Löhr (2008c), 168: "Il Libro dell'arte si mostra vicino piuttosto a concezione della percezione e dell'intelletto tramandate sia dalla trattatistica ottica e medico-psicologica che dalla tradizione enciclopedica, anche se le vere fonti di Cennini sono difficili da determinare.«

75 Dante, Purgatorio 17, 25/Ed. Köhler (2011), 330 (mit Kommentar). Vgl. auch Bundy (1927), 225-256, bes. 239-240; Gmelin Bd. 2, (1968), 273-274 und Köhler (2011), 330 sowie Summers (1981), 119-121.

76 Kemp (1997), 131 nahm »derart hochgesteckte Ziele« an: »Im Namen des Künstlers fordert er die Anwendung der fantasia, der Einbildungskraft, die eine entscheidende Rolle in Dantes Bemühungen gespielt hat, sich der Erkenntnis höchster Wahrheiten zu vergewissern. « Zu Dante vgl. Kemp (1977), 362-363; 363: »his characterization of imagination as an agent of visionary truth « und 396: »Dante had transformed the fantasia of medieval faculty psychology into the highest inventive force in his poetry«. Von einer eingleisigen Transformation und Aufwertung des Begriffes fantasia bei Dante kann nicht die Rede sein. Vgl. die differenzierteren Ausführungen von Bundy (1927) 225-256.

77 Bautier (1988), 82: »Phantasia et imaginatio ont cependant un champ sémantique similaire dans lequel nous discernons deux notions principales: l'>image < et la ^fonction imaginativeく. Dans le premier sens, ils expriment la représentation mentale d'une réalité sensible qui reproduit un objet connu ou qui recrée par similitude. Dérivant de cette notion s'articulent des acceptions secondaires: visions, nocturnes, songes, fantasmes, fantômes, illusions trompeuses, affirmations mensongères ou hérétiques. La seconde notion qui est au coeur des préoccupations de ce colloque, concerne la fonction de l'esprit qui imagine, qui reproduit et recrée. Elle est classée, selon les Théories scientifiques, comme le second des senses internes. Nous verrons que phantasia et imaginatio prennent l'une et l'autre le premier sens mais que phantasia sera très souvent chargée d'une valeur péjorative quasi absente des emplois d'imagination. En revanche chez les théologiens phantasia ne s'applique presque jamais à une faculté de l'âme alors que dans les textes scientifiques ou chez les traducteurs de textes arabes ou hébraiques, c'est deux fois sur trois phantasia qui qualifie le second des sens interne.«Zur Begriffsgeschichte von phantasia und imaginatio vgl. auch Flury (1988); Latham (1988); Spinosa (1988); Busa (1988); Hamesse (1988); Art. »Phantasia« (I. Antike, G. Camassa und E. Evrad; II. Byzanz, L. Benakis; III. Mittelalter und Renaissance, M. R. Pagnoni-Sturlese), Historisches Wörterbuch der Philosophie, Bd. 7, Sp. 516-535. Vgl. Venturi (1964), 85-86 (Fantasia bei Dante); Harvard (1975); Summers (1987); Spruit (1996); Summers (1981), 129; die von Pfisterer (2002), 73-74, 271 angenommene »Gleichsetzung von ingenium und fantasia « bei Cennini lässt sich nicht belegen. 
und dem Verstand. Der menschliche Erkenntnisprozess führt von der sinnlichen Wahrnehmung der Dinge zuerst zur Imagination und dann zur rationalen begrifflichen Erkenntnis. Der menschliche Verstand nimmt die natürlichen Dinge nicht unmittelbar wahr, sondern immer nur die aus Sinneseindrücken hervorgegangenen Phantasiebilder (Schatten). Er ist, wie es auch Dante im Convivio darlegt, auf die Hilfe der Phantasie angewiesen. ${ }^{78}$ Mit dieser Art der Phantasietätigkeit und mit der Frage ihrer Zulässigkeit haben sich Theologen, insbesondere seit dem 12. Jahrhundert, intensiv befaßt. Als Beispiel ist (der von Dante im Paradiso 10,131132 mit besonderer Auszeichnung erwähnte) Richard von St. Viktor in diesem Zusammenhang geeignet, da er in De gratia contemplationis seu Benjamin Maior die Rolle der Phantasie bei der Erkenntnis natürlicher Dinge in seine Überlegungen einbezieht und dabei betont, dass die »im Geist erblickte Form « der sichtbaren Dinge im Grunde nichts anderes sei als ein gemaltes Bild (pictura) unsichtbarer Dinge:

Nunc vero ad id redeamus unde digressi sumus, quomodo scilicet per rerum visibilium imaginationem adiuvemur ad rerum invisibilium investigationem. In eo enim exterior homo in investigationis suae cursu interiorem adiuvat, quo ei invisibilium imaginem per rerum visibilium imaginationem repraesentat. Et, dum ducatus sui officium explet, illuc istum similitudinum calle perducit, quo ille intrare non audet. Sic saepe famuli dominos suos in via usque ad regias fores praeeunt et tamen istis intro usque ad interiora palatii properantibus illi exterius subsistunt. Patet ergo, ut arbitror, quod superius iam diximus, quomodo hoc contemplationis genus esse quidem in ratione et secundam imaginationem intelligere debeamus, quia et invisibilia sunt, quae mente conspicimus, et tamen ex rerum visibilium similitudine illa nobis formamus. Quid enim dixerim rerum visibilium formam nisi quandam quasi rerum invisibilium picturam? Sit modo aliquis qui numquam leonem vidisse se dicat, quem tamen videre desiderat, si ei leonis imago in pictura aliqua convenienter expressa ostenditur, profecto qualem eum cogitare debeat ex eo quod videt statim admonetur. Denique secumdum lineamenta, quae superficietenus expressa considerat, solida membra et vivum animal sibi in mente format. ${ }^{79}$

Nun aber lasst uns zu dem, wovon wir abgeschweift sind, zurückkehren, nämlich wie wir durch die Vorstellung (imaginatio) der sichtbaren Dinge unterstützt werden bei der Untersuchung der unsichtbaren Dinge. Darin hilft der äußere Mensch im Lauf seiner Untersuchungen dem inneren, indem er das Bild der unsichtbaren Dinge durch die Imagination der sichtbaren vor Augen führt. Und indem er seine Führungsaufgabe wahrnimmt, führt er diesen auf dem Weg der Ähnlichkeiten, den jener nie zu betreten wagt. So gehen oft die Diener ihren Herren auf dem Weg bis zu den königlichen Pforten voran und bleiben dennoch, während jene in das Innerere des Palastes eilen, drauBen stehen. Es ist also klar, wie ich meine, was ich schon weiter oben gesagt habe,

78 L'ottimo commento della Divina Commedia, testo inedito d'un contemporaneo di Dante, 3 Bde. Pisa, 1827-1829, Bd. 2, 300: „La fantasia è quella virtù, la quale le forme, secondo loro similitudine, che l'uomo apprese per si sensi particulari, in tutto o in parte apprende.« Vgl. Art. »Fantasia«, Rak (1970), 793-794; Enciclopedia Dantesca, Bd. 3, 1971, 367-368, s.v. imaginare (Lanci), 368-369, s.v. imaginativa (Rak), 369-370, s.v. imaginazione.

79 Richard von St. Victor, De contemplatione (Benjamin Maior), II, 18/Ed. Aris 1996, [44]. 
wie wir verstehen müssen, dass diese Art der Betrachtung in der ratio (im Verstand) und gemäß der imaginatio (der Vorstellungskraft) abläuft, weil auch die Dinge unsichtbar sind, die wir im Geist erblicken, und wir sie uns dennoch aus der Ähnlichkeit mit den sichtbaren Dingen formen. Was nämlich, möchte ich sagen, ist die Form der sichtbaren Dinge, wenn nicht gleichsam ein gewisses gemaltes Bild (pictura) der unsichtbaren Dinge.

Angenommen jemand, der niemals einen Löwen gesehen hat, sagt sich, dass er dennoch einen zu sehen wünscht, der wird, wenn man ihm das Abbild eines Löwen auf irgendeinem gut gemachten Bild zeigt, in der Tat sofort aus dem, was er sieht, angewiesen, wie er sich einen zu denken hat. Schließlich formt er sich gemäß der Zeichnung, die er als oberflächlich ausdrückend betrachtet, die festen Gliedmaßen und das lebende Tier in seinem Geist. ${ }^{80}$

Entscheidend ist in beiden Fällen die Ähnlichkeit, die zwischen sichtbaren Dingen und ihren Abbildern im Geist wie auch zwischen unsichtbaren Dingen und ihren mithilfe sichtbarer Dinge generierten Vorstellungsbildern besteht. Richard von St. Viktor betont dabei ebenso die Distanz zwischen Dingen der äußeren Sinnenwelt und den inneren Vorstellungsbildern (quod in sua cogitazione sibi finxit interius), um das Bewusstsein für die Differenzen zwischen Sinneswahrnehmung, Imagination und Verstand wach zu halten:

Cogita nunc quantum sit inter illud, quod videt exterius, et inter hoc, quod in sua cogitatione sibi fingit interius. Sic sane in hoc contemplationis genere longe a se distant invisibilia, quae in mente versamus, et ea, quae per imaginationem cernimus et tamen ad illa exprimenda ex istis similitudinem trahimus. Reddidimus quomodo potuimus rationem cur hoc genus contemplationis videatur esse in ratione et secundam imaginationem. $^{81}$

Bedenke nun wie viel zwischen dem liegt, was er äußerlich sieht, und dem, was er sich innerlich in seinem Denken bildet. So weit freilich in dieser Art der Betrachtung die Dinge, die wir im Geist erwägen und die, die wir durch die Imagination sehen, von einander entfernt sind, und dennoch ziehen wir die Ähnlichkeit aus diesen um jene auszudrücken. Wir haben, so gut wir konnten, Rechenschaft abgelegt, warum diese Art der Betrachtung in der ratio und gemäß der Imagination zu sein scheint. ${ }^{82}$

Neben ihrem reproduktiven, die sinnlich wahrnehmbaren Dinge dem Verstand vermittelnden Vermögen vermag die Phantasie die von ihr erzeugten und in der memoria aufbewahrten Bilder neu $\mathrm{zu}$ kombinieren und dadurch neue Vorstellungsbilder hervorzubringen. ${ }^{83}$

80 Übers. Ursula Rombach. Siehe Aris (1996) 45-133 für eine Analyse des Traktats und der in ihm enthaltenen Erkenntnislehre und bes. 73-79 zu dem Zitat. Vgl. auch Meier (1988), bes. 48-49 und Kämmerlings (1994), 76-100.

81 Übers. Ursula Rombach. Richard von St. Victor, De contemplatione (Benjamin Maior), II, 18/Ed. Aris (1996), [44].

82 Siehe hierzu Aris (1996), 25-27 (zu der bei Richard von St. Victor vorhandenen »Situierung des Menschen in der >Dimension der Unähnlichkeit « - in regione dissimilitudinis«).

83 Bundy (1927), 182-183 (Avicenna), 188-195 (Albertus Magnus: Unterscheidung von imaginatio und phantasia), 207 (Bonaventura), 212 (Maimonides), 217-218 (Thomas von Aquin: Revision der Unterscheidung von imaginatio und phantasia), 227-228, 231, 237 (Dante); vgl. Chenu 
Cennini hat sich Elemente der mittelalterlichen Fakultätenpsychologie angeeignet, wobei er die philosophische Terminologie weitgehend vernachlässigte und $i h m$ vertrauteres oder angemessener erscheinendes Vokabular bevorzugte. Er bezeichnet »die unsichtbaren Dinge«, die der Maler bei dem Kopieren naturgetreuer Zeichnungen oder beim Zeichnen der Natur »findet«, und »im Geist erblickt« nicht als picturae, sondern aussschließlich als disegni. An ihnen erfreut sich der Intellekt, da die Suche nach Wahrheit das allem übergeordnete Ziel ist. Sie werden im Gedächtnis thesauriert oder, da sie der Maler durch operazione di mano festzuhalten vermag, auch in einer Zeichnungsmappe. Die disegni dienen als Formenfundus, dem die Darstellungsformen für Darstellungsaufgaben jeglicher Art entnommen werden können. Die produktive Verknüpfung von Dingen bezeichnet Cennini zur Unterscheidung von dem primären trovare (der Formen) der Dinge als comporre e legare insieme. Die Selektion basiert auf dem Prinzip der Ähnlichkeit. Somiglianza kommt als Begriff bei ihm nicht vor, ${ }^{84}$ aber der Libro dell'arte enthält konkrete Beispiele, die hinreichend aussagekräftig sind: Ähnlichkeit ist die Voraussetzung des bereits erwähnten Ratschlags, mithilfe der Zeichnung eines Steines zu einer natürlich aussehenden Gebirgsdarstellung zu gelangen. Dasselbe gilt auch für die Angaben dazu (Kap. 160), wie man einen Baum gestaltet, dass er aussieht, als sei er ein Baum des Paradieses (»lavorare alcuno albore che paresse degli albori di paradiso [...] «). Aufschlussreich ist ebenso die Anleitung zur Ausführung eines jugendlichen Gesichts. Sie soll die Fähigkeit vermitteln, alle Figuren zu malen, die sich hinsichtlich eines jugendlichen Gesichts ähneln, unabhängig davon, ob sie gesehene oder nicht gesehene Personen darstellten (»una testa di santa o santo giovane, sì chome è quello di Nostra Donna Santissima $\ll^{85}$ ). In diesen wie in fast allen anderen Fällen steht die verstandesgemäße Anwendung wissensbasierter, lernbarer Verfahren der Formgebung im Vordergrund. Von einer Rolle der Phantasie ist lediglich in Kapitel 140 die Rede, in dem er Gravuren in Goldauflagen behandelt, eine Technik, die er in besonderer Weise schätzte:

Questo granare, che io ti dico, è uno de' belli membri che abbiamo: e pòssi granare a disteso, come ti ho detto, e possi granare a rilievo; che con sentimento di fantasia e di mano leggiera tu poi in un campo d'oro fare fogliami e fare angioletti e altre figure che traspaiono nell'oro $[\ldots . .]^{86}$

Dieses Eingraben, wovon ich zu dir spreche, ist eine der schönsten Techniken, die wir besitzen. Du kannst flach gravieren, wie ich dir gesagt habe, und du kannst reliefartig gravieren.

(1946), 593-602; Prandi (1962), 359-360; Summers (1981), 128-129 (Augustinus, Albertus Magnus, Thomas von Aquin); Eco (1991), 172 (Avicenna, Thomas von Aquin).

84 In Kap. 181 wird jedoch die Naturnachahmung des »disegno mit ritrarre e simigliare chose di natural« beschrieben. Cennini, Il libro dell'arte/Ed. Frezzato (2008), 205.

85 Cennini, Il libro dell'arte/Ed. Frezzato (2008), 113.

86 Cennini, Il libro dell'arte/Ed. Magagnato/Brunello (1982), 143. 
Du kannst mit Gespür der Phantasie und einer leichten Hand auf einem Goldgrund Blätterwerk, Engelchen und andere Figuren machen, welche im Golde glänzen. ${ }^{87}$

Cennini hat die reproduktiven und produktiven Tätigkeiten der Phantasie im ersten Kapitel zwar mit den Begriffen trovare und comporre unterschieden, aber die beiden Vermögen werden an keiner weiteren Stelle hinreichend deutlich ausgewiesen. Das betrifft auch den zitierten Passus. Welche der beiden Arten der Phantasietätigkeit Cennini hier meinte - und ob er überhaupt nur eine meinte -, ist nicht zu ermitteln. Die Verwendung des Verbs fare lässt einen eindeutigen Rückschluss auf das produktive Vermögen der Phantasie nicht zu, da man die Verbindung von sentimento di fantasia und mano leggiera im Libro dell'arte auch in Zusammenhang mit reproduktiver Phantasietätigkeit vorfindet: Das zeichnerische Erfassen der verità setzt nicht nur Intellekt, sondern auch eine geübte Hand voraus, eine mano leggiera, die es ermöglicht, subtile Feinheiten mit exakter Handtätigkeit (operazione di mano) zu erfassen. Auf jahrelanger Übung basierendes zeichnerisches Feingefühl (sentimento) erfordert nach Cennini (naturgegebene) Phantasie. Deutlich wird dies in Kapitel 27, in dem er darlegt, dass die präzise Nachahmung einer maniera nur möglich ist, wenn die Natur dem Maler ein Minimum an Phantasie »geschenkt hat ${ }^{88}{ }^{88}$ Die Phantasie vermag nicht nur aus den Sinnesdaten Vorstellungsbilder zu generieren, sondern sie ist auch die Kraft, die die zeichnerische Feinmotorik ermöglicht, die man benötigt, um Vorstellungsbilder mit der Hand präzise festhalten zu können. Auf diese Auffassung scheint die Wortverbindung sentimento di fantasia hinzuweisen. ${ }^{89}$ Das Prinzip richtigen Zeichnens »Conviene che con intelletto ti guidi« (Kap. 30) ist mit der Erwähnung der Phantasie nicht außer Kraft gesetzt. Gemeint ist, dass »die Hand, die dem Intellekt gehorcht « (Michelangelo: »la mano che ubbidisce all'intelletto «) ${ }^{90}$, nur eine in vollkommener Weise geschulte Hand sein kann. Die operazione di mano basiert auf einem Zusammenspiel von fantasia und intelletto, bei dem die fantasia eine unerlässliche Hilfsfunktion und der intelletto die leitende Funktion erfüllt.

Das Generieren und Kombinieren von »Engelchen und anderen Figuren« setzt jedoch auch die Neukombination im Kopf thesaurierter Formen, der disegni nella testa, und damit produktive Phantasietätigkeit voraus. Auch diese ist nicht losgelöst vom Intellekt, da sie auf wissenschaftlicher Grundlage erfolgt. Auf die Frage nach den Modalitäten der Zulässigkeit von Figuren- und Bildentwürfen, die auf dieser Art der Phantasietätigkeit basieren, ist nun näher einzugehen.

87 Vgl. Cennini, Il libro dell'arte/Übers. Ilg (1888), 88-89 (mit Änderungen). Vgl. Kuhn (1991), 141: »daß du mit Gespür der Phantasie und von leichter Hand in einem Goldgrund Blätter machen kannst, Engelchen machen kannst und andere Figuren, die im Gold erscheinen." Vgl. hierzu Seiler (2012).

89 Vgl. hierzu Löhr (2008c), 174.

90 Michelangelo, Non ha 'ottimo artista alcun concetto/Ed. Frey (1964), 89. 


\section{Erfindungsfreiheit auf wissenschaftlicher Grundlage} (comporre e lleghare)

Die Malerei ist eine Kunst mit wissenschaftlichem Fundament. Das ist das zentrale Thema des ersten Kapitels. Die Phantasie steht nicht an erster Stelle. Über den Stellenwert ihrer kreativen Funktion äußert sich Cennini in Verbindung mit seiner Bestimmung des hohen wissenschaftlichen Rangs der Malerei:

E con ragione merita metterla a ssedere in secondo grado alla scienza e choronarla di poexia. La ragione è questa: che 'l poeta, con la scienzia, per una che à, il fa degnio e llibero di potere comporre e lleghare insieme si e nno come gli piace, secondo suo volontà. Per lo simile, al dipintore dato è libertà potere comporre una figura ritta, a sedere, mezzo uomo mezzo cavallo, si come gli piace, secondo suo' fantasia. ${ }^{11}$

Und mit Recht verdient sie (die Malerei) auf der zweiten Stufe (nach) der Wissenschaft zu sitzen und mit Poesie gekrönt zu werden. Der Grund ist dieser: dass der Dichter mit der Wissenschaft - deswegen hat er eine - würdig und frei ist, ja und nein zusammenzusetzen und verbinden zu können, wie es ihm gefällt, seinem Willen folgend. Auf ähnliche Weise ist dem Maler Freiheit gegeben, eine Figur zusammenzusetzen, aufrecht, sitzend, halb Mensch, halb Pferd, so wie es ihm gefällt, nach seiner Phantasie. ${ }^{92}$

Der Passus folgt unmittelbar im Anschluss an die Feststellung, dass alle Künste (arti bisognevoli) ihre Grundlage der Philosophie verdanken, aber dennoch nicht ebenbürtig sind, da ihr Wissen (ihre scienza) unterschiedlich groß ist und ihre jeweilige Würde hiervon abhängt. Dass der Malerei ein Anrecht auf die zweite Stufe zustehe und zudem eine $»$ Bekrönung mit Poesie $«,{ }^{93}$ wird nicht mit einer Darlegung konkreter Wissensbestände und ihrer Quantität oder Bedeutung begründet, sondern nur mit einem - anhand von Beispielen lediglich illustrierten generellen Hinweis abgesichert: nach Cennini verfügen Dichter und Maler jeweils über eine scienza, die ihnen das Recht und die Würde verschafft, Dinge nach

91 Cennini, Il libro dell'arte/Ed. Frezzato (2008), 62.

92 Cennini, Il libro dell'arte/Übers. Löhr (2008), 10 (mit Änderungen).

93 Ilg in: Cennini, Il libro dell'arte/Übers. Ilg (1888), 4, übersetzte die »Krone von der Phantasie«; ebenso Schlosser (1924), 79; Kemp (1997), 131; Gramaccini (1985), 203; Eusterschulte (2000), 799; Pfisterer (2002a), 263; Blume (2003), 56; Löhr (2008), 10. Häufig wird die »Krönung durch die Poesie« als frühes Zeugnis des in späterer Zeit viel diskutierten Rangstreits von Malerei und Poesie angesehen. Diese Auffassung äußerte bereits Schlosser (1924), 80: »Der Malerei gebührt die zweite Stelle nach der Wissenschaft, neben und vor der Poesie«; vgl. auch Kuhn (1991), 146 mit der Übersetzung »die Krone vor der Poesie«, sowie zuletzt z.B. Scholz, Art. "Bild «, 646: »Hier klingt der Rangstreit der Künste an, in dem die Malerei ihre Leistungen von nun an immer höher veranschlagt. « Bätschmann/Alberti (2007), 30. Richtig ist jedoch die Übersetzung »mit Poesie«: Kruse (2000), 313 und Kruse (2003), 80: »mit Poesie«; Krüger (2001), 123: »als Poesie krönen «; Serchi, in: Cennini, Il libro dell'arte/Ed. Serchi (1999), 9: »al secondo posto, siede la pittura, che si corona di poesia«; Tarr (2003), 41: »to be crowned with poetry." Malerei und Poesie werden von Cennini offenbar durchaus als ebenbürtig verstanden, auch wenn er lediglich die Malerei ausdrücklich auf die zweite Stufe nach der scienza platziert. Diese Auffassung äußert auch Magagnato (1982), VII. 
eigenem Gutdünken zu erfinden (comporre). Er war offenbar der Auffassung, dass dieser Hinweis ausreichendes Gewicht besäße und sich weitere Ausführungen erübrigten. Aufschlussreich ist das Motiv der Krönung, mit dem er das comporre der Maler nachdrücklich als nobelsten Teil ihrer Kunst ausweist.

Bemerkenswert sind vor allem drei Punkte: (1) Cennini fasste die Erfindung der Maler als poetisches, d.h. ein Fiktionen generierendes Verfahren auf. (2) Er hielt die Einbeziehung der Poesie für geeignet, den hohen Ranganspruch der Malerei zu fundieren, obwohl sich sein Rangsystem an dem Maßstab rational fundierten Wissens orientiert und nach thomistisch-scholastischer Lehre der Poesie nur ein marginaler Wissensanspruch zuzubilligen war. ${ }^{94}$ (3) Er unternahm nicht den geringsten Versuch, in Analogie zu poetologischen Rechtfertigungen dichterischer Fiktionen malerische Fiktionen mit einer epistemischen Funktion (Belehrung durch die Vermittlung moralphilosophischer Wahrheiten) zu legitimieren. Insbesondere der letzte Punkt lässt vermuten, dass Cennini sich über die Tragweite und theoretische Brisanz seiner Aussagen nicht hinreichend im Klaren war bzw. dass er mit ihnen keine grundlegend neue, mit gängigen Vorstellungen nicht konform gehende Erweiterung der Zulässigkeit kreativer Phantasie anstrebte.

\section{Bilder als poetische Fiktionen}

Die Aussage, dass das trovare cose non vedute dem Maler ermöglicht, Dinge zu zeigen, die nicht sichtbar vorhanden sind, beschreibt nach der im Vorausgehenden vorgeschlagenen Interpretation eine auf veritas zielende Formfindung und somit keine Erfindung von Fiktionen. Cennini äußert sich erst anschließend zur Fiktionalität von Gemälden. Er tut dies nicht explizit (das Verb fingere kommt nicht vor), aber indem er das Zusammenfügen von gefundenen Formen zu Gemälden als ein dem poetischen Schaffen analoges Verfahren ausweist, bringt er hinreichend deutlich zum Ausdruck, dass es sich bei den von Malern hervorgebrachten Komposita um Fiktionen handelt: um komposite figürliche Dinge, die natürlichen Dingen ähneln (cche paiono naturali), aber in Wirklichkeit keine natürlichen Dinge sind. Die ontologische Bestimmung von Gemälden als Fiktionen war ein Grundpfeiler der traditionellen Bilderlehre. Isidor stellt in seinen Etymologiae (XIX, 16,5) prägnant fest: Pictura autem dicta quasi fictura; est enim imago ficta non veritas. ${ }^{95}$ Alles andere war nach christlicher Auffassung idolatrischer Irrglau-

94 Zum Rang der Poesie in der thomistisch-scholastischen Lehre siehe Cheneval, in: Dante, Das Gastmahl, Erstes Buch/Ed. Ricklin/Chevenal/ (1996), XXIX; Kablitz (2009).

95 Isidor von Sevilla, Etymologiarum sive originum libri XX, Lib. XIX,16,1/Ed. Lindsay (1987): De Pictura. Pictura autem est imago exprimens speciem rei alicuius, quae dum visa fuerit ad recordationem mentem reducit. Pictura autem dicta quasi fictura; est enim imago ficta, non veritas. Hinc et fucata, id est ficto quodam colore inlita, nihil fidei et veritatis habentia. Vnde et sunt quaedam picturae quae corpora veritatis studio coloris excedunt et fidem, dum augere contendunt, ad mendacium provehunt; sicut qui Chimaeram tricipitem pingunt, vel Scyllam hominem sursum, caninis autem capitibus cinctam deorsum. Picturam autem Aegyptii 
be. Das Herstellen von Bildern wurde trotz ihrer Fiktionalität als legitim eingestuft, weil man ihnen als Medien der Erinnerung einen positiven Nutzen zuschrieb: Pictura autem est imago exprimens speciem rei alicuius, quae dum visa fuerit ad recordationem mentem reducit. Entscheidend war der richtige Umgang mit Bildern und dazu gehörte nicht nur die grundsätzliche, zur Vermeidung von Idolatrie notwendige Unterscheidung von bildlicher Fiktion und Wahrheit, sondern auch die Unterscheidung von zulässigen Fiktionen und solchen, die als »Lügen « einzustufen und zu vermeiden waren. Cennini hat sich von traditionellen Auffassungen der christlichen Bilderlehre nicht entfernt. ${ }^{96}$ Ungewöhnlich und bemerkenswert ist nur, dass er die mit dem Verb comporre beschriebene analoge Verfahrensweise dichterischen und malerischen Schaffens zum Anlass nimmt, den Begriff poesia für die Charakterisierung der Malerei zu adaptieren. Bemerkenswert ist dies vor allem, weil er mit dieser Adaption zugleich einen (ungewöhnlich hohen) Ranganspruch verknüpft. Ohne eine Aufwertung der Poesie wäre dies nicht möglich gewesen. Dante rückt hier erneut ins Blickfeld.

Dante hat sich von der thomistisch-scholastischen Geringschätzung der Poesie, die deren Fiktionen nur einen minimalen Wahrheitsgehalt zubilligte, distanziert. Im Convivio, in dem er die Gedichte seiner Frühzeit kommentierte, reklamierte er für die Poesie mit allem Nachdruck einen philosophischen Status. Cenninis Argumentation setzt dieses »Projekt einer philosophischen Poesie«, das von Boccaccio und Petrarca aufgegriffen und modifiziert wurde, voraus. ${ }^{97}$ Durch diese Aufwertung der Poesie erhält sein Rückgriff auf die ut pictura poesisTradition erst inhaltliches Gewicht.

Cennini beachtet dabei nicht, dass seine Argumentation mit seiner zuvor geäußerten Vorstellung einer Ungleichheit aller Artes bezüglich ihrer jeweiligen scienza nicht ohne weiteres vereinbar ist. Er beschänkt sich in seinen Ausführungen darauf, die Feststellung zu erläutern, dass das poetische comporre ein Verfahren ist, von dem Maler und Dichter gleichermaßen Gebrauch machen. Eine Rivalität im Sinne des späteren Paragone ist nicht zu erkennen. Trotz der

excogitaverunt [...]. Isidor von Sevilla Übers. Möller (2008), 682: »Von der Malerei (Pictura). Die Malerei aber ist ein Bild, das den Anblick einer Sache ausdrückt, die, wenn man sie gesehen hat, den Geist zur Erinnerung zurückführt. Pictura aber heißt gleichsam fictura [Bildung, Erfindung, PS], es ist nämlich ein erfundenes Bild, nicht Wirklichkeit. Daher kommt auch fucata (geschminkt), d. h. mit unechter (fictus) Farbe bestrichen, was nichts an Glaubwürdigkeit und Wahrheit besitzt. Woher es auch einige Malereien gibt, die über die Körper, wie sie in Wahrheit sind, im Eifer der Farben hinausgehen und die Wirklichkeitstreue, während sie sich bemühen, diese zu vergrößern, in Täuschung verwandeln. Wie jemand, der eine dreiköpfige Chimäre malt oder Skylla mit menschlichem Oberkörper und unten mit Hundsköpfen gegürtet. Das Malen aber haben die Ägypter ausgedacht [...].«

96 Warnke (1997), 260, vermutet dagegen, dass Cenninis »kunstheoretische Äußerung zur Phantasie [...] aller kirchlichen Funktionsbestimmung der Malerei widerspricht $\ll$.

97 Cheneval (1996), XXXII; zu Boccaccio und Petrarca vgl. Kemp (1977), 356 und 385-386, 395 (»The visual arts thus take second place«). Die von Summers (1981), 38, und im Folgenden ebenso von Kruse (2000), 309 angedeutete Nähe Cenninis zu Boccaccio und Petrarca lässt sich nicht erhärten. 
unterschiedlichen Wortwahl »come gli piacie, secondo suo volonta (beim Dichter) und »chome gli piace, secondo suo' fantasia« (beim Maler) haben die beiden Formulierungen dieselbe Bedeutung. ${ }^{98}$ Für diese Lesart spricht auch die Begründung ihrer analogen Erfindungsfreiheit von Dichtung und Malerei. Wichtig ist bei beiden die Teilhabe an der scienza, d.h. sie verfügen über ein in der Philosophie (la scienza) fundiertes (gesichertes, vernünftiges) Wissen. ${ }^{99}$ Der Rekurs auf ihre scienza zeigt auch deutlich, dass hier keine über den Regeln ihrer jeweiligen Kunst stehenden künstlerischen Freiheiten reklamiert werden.

Die Ebenbürtigkeit der Erfindungen von Dichter und Maler war kein neuer Gedanke. Bereits im späten 13. Jahrhundert hat Guilelmus Durandus ihn mit Berufung auf Horaz zum Ausdruck gebracht. ${ }^{100} \mathrm{Er}$ hielt es für zulässig, dass Maler die biblischen Historien weitgehend nach ihrem Willen ausgestalteten: Sed et diverse ystorie tam novi quam veteris testamenti pro voluntate pictorum depinguntur; nam pictoribus atque poetis quelibet audendi semper fuit equa potestas. ${ }^{101}$ Auf ikonographische Freiheiten der Maler im Bereich der religiösen Bildkunst bezieht sich Jahrzehnte später Boccaccio, um die Freizügigkeiten seines Decamerone zu rechtfertigen (Decameron, Conclusione dell'autore, 6). ${ }^{102}$ Das

98 In philosophischen Diskursen bezeichnen Wille und Phantasie unterschiedliche Seelenvermögen und sie stehen vor allem zu Vernunft und Intellekt in unterschiedlicher Verbindung. Ramelow, Art. »Wille« (II. Mittelalter und frühe Neuzeit, 770-795, bes. 771, T.-A. Ramelow), Historisches Wörterbuch der Philosophie, Bd. 12. Da Cennini jedoch in seinem Libro dell'arte beide Begriffe als Synonyme verwendet, kann man auch im Kontext der Beispiele für die Erfindungsfreiheit der Dichter und Maler keine distinkte Bedeutung zuschreiben. Auch wenn man Cennini nicht unterstellen kann, ihm sei der Unterschied von Wille und Phantasie völlig entgangen, ordnet er hier die Kreativität von Malern und Dichtern keineswegs getrennten Seelenvermögen zu. Beide besitzen die Freiheit, die Produkte ihrer Phantasie nach eigenem Gutdünken im Rahmen ihrer scienza in ihren Werken zu verwenden. Tarr (2003), 41 versucht ohne hinreichende Anhaltspunkte Cenninis Begriffzuordnung mit Filippo Villani in Verbindung zubringen. Vgl. hierzu auch Löhr (2008c), 183.

99 Irreführend ist die Gleichsetzung von scienza und »Begabung« bei Pfisterer (2002a), 263; er übersetzt: »Ebenso wie der Dichter kraft seiner Begabung das volle Recht und die volle Freiheit hat $[\ldots] . \ll$

100 Chastel (1977), 33: »Plus précis, plus explicite ce pro voluntate annonce le sì come gli piace [...] de Cennini.« Kemp (1977), $368 »[$ Cennini] was using just such a medieval version«; vgl. auch Kemp (1997), 124; Summers (1981), 494, Anm. 93; Eco (1991), 161. Zur Rezeption der HorazStelle im Mittelalter vgl. die Literaturangaben bei Pfisterer (2002), 48, Anm. 31.

101 Guilelmus Durandus, Rationale divinorum officiorum I, 3, 22/Ed. Davril/Thibodeau (1995), CCCM 140, 42.

102 Boccaccio, Decamerone (Conclusione)/Ed. Branca (1996), IV, 910: „Sanza che alla mia penna non dee essere meno d'auttorità conceduta che sia al pennello del dipintore, il quale senza alcuna riprensione, o almen giusta, lasciamo ste che egli faccia a san Michele ferire il serpente con la spada o con la lancia, e a san Giorgio il dragone dove gli piace, ma egli fa Cristo maschio e Eva femina, e a Lui medesimo, che volle per salute della umana generazione sopra la croce morire, quando con un chiovo e quando con due i piè gli conficca in quella. « Übers. Brockmeier (2012), 846: „Außerdem sollte man meiner Feder keine geringere Fähigkeit als dem Pinsel des Malers zubilligen, der ohne jeglichen, wenigstens gerechten Tadel - lassen wir einmal beiseite, ob der den Heiligen Michael die Schlange mit dem Schwert oder mit der Lanze, den Heiligen Georg den Drachen, wo es ihm gefällt, treffen lässt - Christus als Mann und Eva als Frau 
Anliegen, den wissenschaftlichen Status der Malerei mithilfe der ut pictura poesis-Formel zu fundieren, ist jedoch bei beiden Autoren nicht vorhanden.

\section{Die Beispiele freier Gestaltung}

Die Freiheit des Dichters wird als ein Zusammenstellen und Vereinen von »ja« und »nein« erläutert, die des Malers durch zwei Gestaltungsmöglichkeiten: die Freiheit, eine Figur aufrecht oder sitzend darzustellen sowie die Kombination von Menschen- und Pferdekörper. Die Freiheit des comporre wird also als Freiheit zur Hervorbringung von Fiktionen bestimmt. Zur Beziehung von Fiktionen und Wissen (scienza) erhält man keine weiteren Hinweise, obwohl diese explizit zur Begründung poetischer und malerischer Freiheit herangezogen wird. Erneut liefert Cennini nur das Gerippe einer Argumentation.

Eine mögliche Quelle für das comporre e legare insieme von »ja« und »nein« ist die Divina Commedia. Im Purgatorio (10,55-63) thematisiert Dante anhand einer eigenen dichterischen Fiktion die synästhetische Wirkung bildkünstlerischer Erfindungen. Es handelt sich um das zweite von drei in diesem Gesang beschriebenen Reliefbildern, die in der Wand des Läuterungsbergs Beispiele der Demut darstellen: um den Tanz Davids vor der Bundeslade. Zweimal gebraucht Dante die Verbindung von »ja« und »nein«, um die Widersprüchlichkeit der durch dieses Relief ausgelösten unterschiedlichen Sinneswahrnehmungen zum Ausdruck zu bringen: Zunächst beschreibt er einen Widerspruch von Sehsinn und Gehörsinn, dann einen Widerspruch von Sehsinn und Geruchsinn:

\section{Era intagliato li nel marmo stesso lo carro e' buoi, traendo l'arca santa, per che si teme officio non commesso. \\ Dinanzi parea gente; e tutta quanta, partita in sette cori, a' due mie' sensi faceva dir l'un ,No', l'altro ,Si, canta'. \\ Similmente al fummo delli 'ncensi che v'era intagliato, li occhi e 'l naso e al sì al no discordi fensi.}

Eingemeißelt in den Felsen war dort der Ochsenkarren, der die Heilige Lade zieht seither scheut man ja ein Amt ohne Auftrag. Davor waren eine Menge Leute zu erkennen, aufgeteilt in sieben Chöre, und von meinen Sinnen sagte mir der eine:

darstellt, und Ihn selbst, der um der Menschheit Heil am Kreuz sterben wollte, einmal mit einem, dann wieder mit zwei Nägeln die Füße festnagelt.« Ein ähnlicher Passus zur Rechtfertigung künstlerischer Lizenz, der auch die profane Malerei berücksichtigt, ist im letzten Kapitel der Genealogie deorum gentilium enthalten. Boccaccio, Genealogie Deorum Gentilium XIV, 18/Ed. Branca (1998), VII-VIII/2, 1474. Vgl. Gilbert (1991), 56-61 und (1991a), 167196; Watson (1984), 60-64; Blume (2003), 53-55. 
»Sie singen >ja«« und der andere: »Ich höre aber nichts.« Ganz ähnlich erging es beim Weihrauch, der dort abgebildet war, den Augen und der Nase: Sie konnten sich nicht einigen. ${ }^{103}$

Es handelt sich bei diesem wie auch bei allen anderen im Purgatorio beschriebenen Reliefskulpturen um imaginierte Produkte einer übernatürlichen, den höchsten Perfektionsgrad erreichenden Bildkunst Gottes. Mit den Ambivalenzen der Sinneseindrücke, die durch das Relief, das die alttestamentliche Szene des demütigen David darstellt, hervorgerufen werden, fingiert Dante Vorzüge jenseitiger Kunst. ${ }^{104}$ Es läßt sich nicht klären, ob die im Libro dell'arte enthaltene Formel des comporre e legare insime si e no come gli piace direkt durch diese Bildbeschreibung angeregt wurde. ${ }^{105}$ Aber auch wenn es tatsächlich der Fall gewesen wäre, dann bliebe Cenninis Rückgriff auf Dante weitgehend unverständlich, da nicht deutlich wird, ob er das $\mathrm{Si}$-e-No-Motiv dem Dichter zuordnete, weil es einer dichterischen Fiktion Dantes entstammte, oder ob er bezweifelte, dass menschliche Malerei diese geschilderten Wirkungen zu ihren höchsten Zielen rechnen sollte.

Das erste der beiden Beispiele zur Erläuterung der Erfindungsfreiheit des Malers, der Hinweis auf die Variationsmöglichkeit, Figuren »sitzend oder aufrecht" darzustellen, stand in enger Verbindung zur malerischen Praxis. ${ }^{106}$ Modifikationen von Körperhaltungen gehörten zu den alltäglichen Kompositionsaufgaben, und waren bei Aufträgen gelegentlich auch Gegenstand vertraglicher Regelungen. So ließ sich z.B. Neri di Bicci derartige Gestaltungsspielräume ausdrücklich zusichern: »1462 darf er einen Heiligen Hieronymus >kniend oder stehend, wie es mir gut scheint<, 1473 einen Johannes >entweder kniend oder stehend, wie es mir am besten erscheint`, malen. ${ }^{107}$ Die Entscheidung darüber, ob Maria und Johannes unter dem Kreuz stehen oder sitzen, ob der Erzengel Gabriel und Maria bei der Verkündigung stehen oder knien oder auch ob Josef alt und jung dargestellt wurde, ${ }^{108}$ beanspruchten Künstler als eine Domäne ihres Willens und ihrer Imagination.

103 Übers. Köhler (2011), 189.

104 Zu dieser Bildbeschreibung Dantes vgl. Kablitz (1998), 332.

105 Eine direkte Verbindung zu den von Summers (1981), 493, Anm. 91, aufgeführten Stellen bei Aristoteles, De anima, 427b20, 428a10, 432a10)/Ed. Ross (1956), Übers. Krapinger (2011), ist nicht zu erkennen.

106 Mit dem ersten Beispiel sind weder in Analogie zur Poesie rhetorische Figuren als Schmuck gemeint, wie Summers (1981), 88, annahm, noch »Zufallsbilder«, wie Gramaccini (1985), 202, glaubte annehmen zu können. Kritisch zu diesen Überlegungen äußert sich bereits Löhr (2008b), 171. Der deutliche Praxisbezug dieses Beispiels wird von Belting (2001a) nicht berücksichtigt: $» D i e$ Phantasie kommt, als Rechtfertigung der Kunst als Kunst, seltsamerweise erstmals bei dem Florentiner Werkstattpraktiker Cennino Cennini zu Ehren, übrigens ohne Bezug zur Kunstpraxis der Zeit um 1400.«

107 Warnke (1997), 260 und (1997a), 31 mit weiteren Beispielen.

108 Gerson entschuldigte mit dem Horaz-Dictum, dass von Deutschen Josef in aetate iuvenili dargestellt wurde (Opera omnia, Anvers 1706, III, col. 1352) zit. nach Schapiro, (1945), 182187. 
Das dritte Beispiel, das Kentaurenmotiv, das häufig ausschließlich Aufmerksamkeit findet, ähnelt zwar der Beschreibung der widernatürlichen Kreatur ${ }^{109}$, die Horaz in der ersten Zeile (zu Beginn) der Ars poetica imaginiert; ${ }^{10}$ es handelt sich aber keineswegs um ein »unausgewiesenes Horaz-Zitat. « ${ }^{111}$ Der römische Dichter verwendet das Mischwesen zudem als Negativbeispiel, um unzulässige, lächerliche Regelüberschreitungen zu kritisieren: Bereits Isidor von Sevilla adaptierte und modifizierte das Beispiel für seine Ausführungen zur Malerei, um zu verdeutlichen, dass übereifrige Maler Fiktionen hervorbringen, weil sie über die Körper, wie sie in Wirklichkeit sind (corpora veritatis), hinausgehen und sich zu Lügen hinreißen lassen ( $a d$ mendacium provehunt). ${ }^{112}$ Mutmaßungen darüber, ob Cennini bei dem Versuch Horaz als Authorität aufzurufen, ein grobes Missverständnis unterlief ${ }^{113}$ oder ob eine bewusste »antihorazische« Erweiterung der bildkünstlerischen Lizenz vorliegt, ${ }^{114}$ fehlt daher eine hinreichende Grundlage. Dass eine direkte Horaz-Referenz wenig wahrscheinlich ist, zeigen auch die Unterschiede zur Ars poetica: (1) Zwei der drei Erläuterungen kommen in Ars poetica nicht vor. (2) Der Kentaur, der als Ersatz für das Mischwesen der Ars poetica zu fungieren scheint, steht erst an zweiter Stelle der beiden dem Maler zugeordneten Beispiele. (3) Horaz erwähnt sein Mischwesen als Beispiel für einen Mangel an formaler Einheitlichkeit; Bücher, die solchen Gemälden ähnelten, seien wie Wahngebilde, die in Fieberträumen entstehen: sie entstünden aus einer Unkenntnis der Kunstregeln (si caret arte); im Libro dell'arte spielt die Forderung nach formaler und inhaltlicher Angemessenheit keine Rolle. Cennini fordert auch nicht das Recht, die Regeln der Kunst zugunsten der Phantasie auszublenden. Im Gegenteil: Er beruft sich auf die verstandesgemäßen Grundlagen der Malerei: Der Maler habe auf der Grundlage seiner scienza das Recht, auch Mischwesen wie den Kentaur zu erfinden. Mischwesen waren in der malerischen Praxis nicht unbekannt. Sie wurden freilich überwiegend in (dekorativen) Randbereichen (und nur in Sonderfällen in narrativen Bildern (Historien) verwendet. Dass sie auch von Cennini als grundsätzlich zulässig eingestuft wurden, macht ihn noch nicht zum künstlerischen Nonkonformisten und Bahnbrecher ungewöhnlicher künstlerischer Freiheiten. ${ }^{115}$

109 Horaz, Ars poectica 1-2 (Übers. Färber [1985], 539): Humano capiti cervicem pictor equinam / iungere si velit - »Ein Menschenhaupt mit Pferdes Hals und Nacken: denkt euch, so schüfe es die Laune eines Malers.«

110 Schlosser (1924), 80: »unmittelbar« oder »auf einem Umwege« aus dem »vielgelesenen [...] Schulbuch bezogen «.

111 Vöhringer (2010), 25; ebenso nimmt Kruse (2003), 80, an, dass Cennini Horaz »zitiert«.

112 Vgl. hierzu Assunto (1961), 61-62.

113 Kruse (2000), 313 und Kruse (2003), 80; Puttfarken (2000), 50; Zweifel an einer direkten HoazKenntnis Cenninis äußert Löhr (2008b), 169 und Löhr (2008c), 183.

114 Wanke (1997a), 31 fasste die »Lizenz zu tierischen Drôlerien« als »antihorazische Erinnerung« auf; vgl. auch Warnke (1997), 259-260; vgl. auch Summers (1981), 51 und 133.

115 Boscovits (1973); Chastel (1977), 33: »La déclaration de Cennino ne concerne pas les programmes de la peinture; il ne revendique pas pour elle le droit de déployer des scènes mythologiques; la phrase a plutôt une valeur de principe. Mais alors, elle doit peut-être se com- 


\section{fantasia, pratica und saper d'intelletto}

Der Libro dell'arte enthält eine Reihe von Beispielen für künstlerische Gestaltungsfreiräume, Lizenzen, die für Cenninis Verständnis des Verhältnisses von Phantasie und Intellekt/Wissen aufschlussreich sind. Von Entscheidungsfreiheit ist vor allem dann die Rede, wenn rationale Erwägungen nicht verbindlich vorgeben, was zu tun ist. Aus dem Wissensfundus, der zur Malerei als scienza gehört, ergeben sich Regeln und Verfahrensweisen, die grundsätzlich zu befolgen sind. Cennini fordert deshalb von denjenigen, die die Malerei erlernen wollen, die Sekundärtugend ubidienza (Kap. 2 und 3). ${ }^{116}$ Gelegentlich führen jedoch unter-

prendre par référence à quelque position contraire, qui serait d'actualité, comme une allusion que tout le monde pouvait comprendre à une discussion connue. [...] Mais enfin, quel besoin d'introduire les centaures? Sinon pour défendre une fois de plus la légitimité de l'art et des ornements de fantaisie contre ceux qui tiennent pour la règle ascétique et raniconiste de SaintBernard. N'est-ce pas celui-ci qui, dans un texte appelé à un grand retentissement, jusqu'à SaintAntonin, Savonarole et au Cardinal Paeoletti, s'écriait: `Quid facit illa ridicula monstroistas? Quid centauri? Quid semihomines?< [...] L'allusion au >centaure<, l'affirmation toute théorique sur >sì come gli piace〈, a bien pu être depuis le XIIIe siècle une petite contre-attaque habituelle contre toute manifestation d'intolérance. « Mehr Gewicht glaubt Pfisterer (1996), 114, Cenninis Äußerung beimessen zu können: »Die radikalste Forderung deduziert jedoch zu Beginn des Quattrocento Cennino Cennini in seinem Lehrbuch der Malerei aus den ersten Zeilen der Horazschen Dichtkunst«. Überbewertet wird Cennninis Äußerung auch von Kruse (2003), 132: »Das theoretische Konzept des Capriccio ist bereits bei Cennino Cennini in nuce vorhanden«.

116 Obwohl Cennini ubidienza fordert, vermeidet er gleichwohl bei der Beschreibung der vielfältigen handwerklichen Tätigkeiten des Malers Formulierungen zu wählen, die explizit verdeutlichen, dass er vielfach etwas tun muss, weil er von Aufträgen und Auftraggebern abhängig ist. In Kap. 144 formuliert er den hiermit verbunden sozialen Anspruch: $» E$ sappi ch 'l lavorare di tavola è proprio da gentile huomo, che co' velluti indosso puoi far ciò che vuoi.« (Cennini, Il libro dell'arte/Ed. Frezzato [2008], 168); Frezzato weist in Anm. b auf eine ähnliche Bemerkung Leonardos, die jedoch im Kontext des Paragone von Malerei und Skulptur steht). Cenninis Bevorzugung und häufige Verwendung des Modalverbs »wollen« ist evident und lässt erkennen, dass es ihm generell wichtig ist, das Tun des Malers nicht als ein von äußeren sozialen Zwängen und Verbindlichkeiten bestimmtes Tun erscheinen zu lassen, sondern als eine weitgehend auf individuellen Willensentscheidungen des Malers basierende Tätgkeit, die lediglich den Regeln der arte di dipingere verpflichtet ist. So werden auch technische Anleitungen, wie man etwas machen soll, überwiegend mit Wendungen wie »Wenn du $\mathrm{x}$ machen willst, musst du y tun « zum Ausdruck gebracht: Kap. 16, 73; Kap. 17, 74; Kap 20, 76; Kap. 24, 78; Kap. 25, 79; Kap. 49, 98; Kap. 54, 100; Kap 55, 100; Kap. 56, 101; Kap. 57, 101; Kap. 58, 102; Kap. 59, 102; Kap. 60, 103; Kap. 62, 103; Kap. 62, 105, 107; Kap. 66, 110; Kap. 67, 110; Kap. 68, 116; Kap. 69, 117; Kap. 71, 118; Kap. 72, 120; Kap. 73, 122; Kap. 74, 122 ; Kap. 75, 122; Kap. 76, 123; Kap. 77, 123; Kap. 78, 124; Kap. 79, 124; Kap. 80, 124; Kap. 81, 124; Kap. 82, 125; Kap. 83, 125; Kap. 84, 126; Kap. 85, 126; Kap. 86, 127; Kap. 87, 127; Kap. 88, 129; Kap. 98, 134; Kap. 101, 135; Kap. 124, 151; Kap. 131, 155; Kap. 134, 156; Kap. 136, 159; Kap. 141, 162; Kap. 142, 164; Kap. 143, 165; Kap. 144, 166; Kap. 144, 169; Kap. 145, 169; Kap. 150, 173; Kap. 151, 174; Kap. 152, 175; Kap. 153, 176; Kap. 155, 178; Kap. 157, 179; Kap. 158, 179; Kap. 160, 180; Kap. 162, 183; Kap 163, 185; Kap. 170, 189; Kap. 172, 194; Kap. 173, 196; Kap. 174, 198; Kap. 174, 199; Kap. 175, 201; Kap. 179, 203; Kap. 180 , 204; Kap. 182, 205, 206; Kap. 187, 210; Kap. 189, 211; Kap. 198, 212. An anderen Stellen steht statt se vuoi fare gelegentlich die Wendung per fare. (z.B. Kap. 21, 77). Formulierungen, die 
schiedliche oder sogar beliebig viele Wege zum Ziel, woraus sich für den Maler Wahlfreiheiten ergeben. Cennini weist auf solche Fälle der Wahlfreiheiten mit stereotypen Wendungen immer wieder hin: außer der bereits in Kapitel 1 vorkommenden Formel »chome ti piacie« gebraucht er auch »chome tu vuoi, secondo che vuoi, chome a tte parrà und andere. ${ }^{117}$

äußere Zwänge, Vorgaben und Abhängigkeiten implizieren sind nicht nur weit weniger häufig, sondern sie häufen sich in den Teilen des Libro dell'arte, die von Cennini nachträglich ergänzt wurden (Kap. 162-189). Vgl, hierzu Seiler (2012) 45-46: Kap. 67, 111: »Poi, secondo la storia o ffighure che 'dde' fare [...]«; Kap. 72, 120: »Mo si à' tu a 'llavorare uno azurro biancheggiat [...]; Kap. 88, 135 Imprima impara a ttagliare le stelle, tutte cholla righa; e dove l'ài a mettere [...]; Kap. 163, 183 Se tu havessi havere a lavorare in tela [...] «; Kap. 165, 185: »Se ài a llavorare in zendad $[\ldots]$ / Se ài a disegnare di notte [...] / Se nonn-è sole, e ài a disegnar [...] / quel che ài a disegnare [...]; »dove ài a ccholorire [...]«; Kap. 166, 186: »Se avessi a llavorare in velluti $[\ldots] \ll$; Kap. 166, 186; Kap. 167, 186: »Se chaso t'aviene d'avere a llavorare in panno di lana [...]; Kap. 167, 187 dove ài a mettere d'oro [...]«; Kap. 169, 188: »Quando ti viene il chaso di fare alchuno cimieri o elmo [...] / E di questo giesso va' ponendo e bozzando, dandogli quella forma o d'uomo o d'animale che abbi a ffare, o d'uccielo [...] ; Kap. 171, 192: »E se t'avenisse a ffare fighurette picchole [...] «; Kap. 174, 200: $)$ E se pur ti venisse caso che per alcuno lavorio [...] ; Kap. 178, 202: »Troverrai alchuni che tti faranno fare in tavola in verdi [...] ; Kap. 179, 203: »Usando l'arte, per alchune volte t'adiverrà avere a ttigniere o dipingnere in carne $[\ldots] \ll$.

117 Die Wahl- und Gestaltungsfreiheiten reichen von zeichnerischen Entwürden von Figuren und Historien bis hin zu technischen Einzelheiten: Kap. 1, 62: »sì chome gli piace, secondo suo' fantasia«; Kap. 12, 70 »e torrai via quello che vorrai«; Kap. 13, 70: »Praticato che ài in questo essercizio un anno e più e meno, secondo che apetito, diletto, tu arai preso«; Kap. 14, 72: „e 'ffa' la temperatura grossa e sottile secondo che voi, o per disegniare o per iscrivere«; Kap. 15, 72: »e poi fare le tuo' tinte o in rosetta, on in biffo, $o$ in verde, o azurrine, o berettine, cioè colore bigie, o incarnate, o come ti piacie«; Kap. 17, 75: „Vero è ch'a 'lcuni piacie molto brunire pur su la carta tinta, cioè che lla pietra da brunire la tocchi e cerchi perché l'abbi un poccho di lustro; poi fa' chome a tte piacie, ma 'l mio primo modo è migliore / fa' chome tu vuoi«; Kap. 23, 78: »sì chome tu ài i piacieri su«; Kap. 24, 78: »Se la vuoi più lucida«; Kap. 29, 82: »o storia e ffigura che vuogli ritrarre«; Kap. 33, 87: »e per lo simile può far de' charbon grandi e de' piccholi e far chome ti piacie, ché miglior charboni nonn-è al mondo«; Kap. 34, 87: »E disegnia sechondo che huoi«; Kap. 36, 88: »chome le piacie«; Kap. 62, 105: »Diliberati in te medesimo di quante ragioni tu vuoi azuri, o di tre, o di quattro, o di sei [...] «; Kap. 67, 113: »e' ti paresse / secondo che a tte paresse« (Ende der Kapitelserie zum Zeichnen); Kap. 38, 91: „Chome n'ài bisognio, tra'ne quel ch tti pare, che 'l detto cholore « [eine Mischung von cinabrese und bianchozo PS] ti fa grande honore di cholorir vuolti, mani e igniudi in muro, chome detto ò, e talvolta ne può fare di belli vestiri, che in muro paiono di cinabro«; Kap. 67, 112: »Poi fa' prima i tuo' fregi o altre cose che voglia fare d'attorno; e cchome a 'tte convien«; Kap. 71, 118: »un vestire di qual vestir tu voi / o cchome tu vuoi«; Kap. 72, 121: „va' colorire chome tu voi«; Kap. 78, 124: »o vuoi di nero, o voi di biffo, o vuoi di verde schuro«; Kap. 87, 127: »nella grandezza che vuoi / di quel colore tu voi«; Kap. 90, 130: »o vuoi chon ispugnia, o vuoi col pennello morbido et mozetto«; Kap. 103, 136: »Quando non vuoi adornare le tue figure di stagnio, puo' adornare di mordenti Kap. 124, 151: »e andare prestamente a rrilevare quello che vuoi«; Kap. 128, 153: »divise di que' ragion che vuoi«; Kap. 132, 155: „Anchora si può fare la detta tempera inn- un'altro modo«; Kap. 137, 159: »E gli è vero che di verno tu poi mettere d'oro quando vuoi«; Kap. 140, 162: »disegna in sul campo dell'oro quello che tu vuoi fare, con stile d'argento, over d'otone«; Kap. 142, 164: "gratta qual tu voi «; Kap. 156, 170: »E 'sse volessi drapparli d'oro, anche il puo' fare«; Kap. 143, 164f.: "quel vestire che vuoi fare / il drappo che vuoi fare di quel cholor tu vòi«; Kap. 144, 166: »di quel colore che vuoi«; Kap. 167: »E per quest modo puoi fare de' 
Explizite Angaben dazu, welches geistige Vermögen in solchen Fällen als Entscheidungsinstanz fungiert, sind nur in sehr wenigen Fällen vorhanden. Zweimal rekurriert Cennini auf den Intellekt: Kapitel 144: »E per questo modo puoi fare de' drappi assai e di più ragioni, secondo tuo intelletto e chome di ciò ti diletterai $^{118}$ und Kapitel 170: "Qui fa' intagliare fighure, animali, divise, fiori, stelle, rose, e d'ogni manieri che nello intelletto tuo disideri. ${ }^{119}$

In Kapitel 172 fordert Cennini offenbar zur Absicherung einer guten Entscheidung zu einer religiösen Invokation auf: »e chol nome di Dio inchomincia leggiermente a disegnare con questa ghugiella quella fighura che voi fare ${ }^{120}$ In Analogie zu der in Kapitel 1 enthaltenen Verknüpfung »come ti piace, secondo tua fantasia" wären auch Hinweise auf die Phantasie möglich und zu erwarten gewesen. Cennini bringt jedoch nur in Kapitel 173 in Verbindung mit seinen Ausführungen zum Zeugdruck fantasia erneut ins Spiel. Die Rede ist von den Gestaltungsmöglichkeiten farblicher Kontraste. Unerwartet und eher beiläufig, aber gleichwohl mit dem Anspruch einer grundsätzlichen Erkenntnis, weist er der Phantasie an dieser Stelle eine relative Autonomie gegenüber dem intelletto zu. Sie fungiere als Vermögen, das es ermöglicht, in der künstlerischen Praxis Erfahrungswissen zu erwerben, das mit dem Wissen des Intellekts durchaus kompatibel sei. Das liege daran, dass jede Kunst von Natur aus über die Anlage zur Ausbildung von Fähigkeiten und Wohlgefallen verfüge:

drappi assai e di più ragioni, secondo tuo intelletto e chome di ciò ti diletterai«; Kap. 145, 168: »E sappi che'l lavorare di tavola è proprio da gientile huomo, che co' velluti indosso puoi far ciò che vuoi«; Kap. 157, 178: »disegni fighure, fogliami, lettere, o quello che ttu voi«; Kap. 163, 184: »e colorisci vestimenti, visi, montagne, casamenti, e quello che a te pare«; Kap. 164, 184: »disegna quello chevuoi«; Kap. 167, 187: »e metti di quell'oro o ariento che atte pare«; Kap. 170, 189: „Qui fa' intagliare fighure, animali, divise, fiori, stelle, rose, e d'ogni manieri che nello intelletto tuo disideri«; Kap. 190: »E per questo modo ne fa' quella quantità che voi«; Kap. 191: „con ciò che cholor tu vuoi«; Kap. 172, 193: »taglialo di quella quadra che vuoi / e chol nome di Dio inchomincia leggiermente a disegnare con questa ghugiella quella fighura che voi fare«; Kap. 173, 195: »in lla quale vuole essere disegnata d'ogni ragion drappo di seta che vuoi, o di foglie o d'animali«; Kap. 196: »e va' chompartendo di questo giallo o animali o fighure o ffogliami, chome a tte parrà«; Kap. 173, 197: »e più chiari e più scuri sechondo che a tte parrà che per tua fantasia possa comprendere«; Kap. 174, 198: »e fanne per questo modo tanto che a tte basti / mettila in luogho che asciughi bene, o vento o sole, chome a tte piacie«; Kap. 177, 202: „o vuoi con colore nero, cioè di carbone di viti trito bene e temperato con uovo, o vuoi pure rossume d'uovo a l'albume insieme«; Kap. 179, 203: „I tuoi colori puoi fare temperati chon uovo; o vuoi, per caleffare, ad olio o con vernicie liquida«; Kap. 184, 206: „Abbia apparecchiato giesso bolognese, o vuoi volterrano«; Kap. 185, 209: »la predetta forma, overo impronta, tu lla puoi buttare che metallo tu voi; mai o ti consiglia di ciera«; Kap. 187, 211: »e falla sodetta attuo modo, sì chome ti pare«; Kap. 189, 211: „Abbi una chatinella meza d'acqua chiara o piena, come tu vuoi«; Kap. 212: »e asciugha la detta cienere al sole o cchome tu vuoi.«

118 Cennini, Il libro dell'arte/Ed. Frezzato (2008), 167.

119 Cennini, Il libro dell'arte/Ed. Frezzato (2008), 189.

120 Cennini, Il libro dell'arte/Ed. Frezzato (2008), 193. 
Cap. 173 [...] Se lla tela è negra la puoi lavorare d'un biavo ben chiaro, cioè biacha assai e poccho indacho, mischolato, macinato e temperato sechondo usanza che detto t'ò degli altri cholori. Se lla tela è biava togli della biacha macinata e risecchata, e temperata sechondo il modo degli altri cholori. E gieneralmente, sechondo che truovi i champi, sechondo tu puoi trovare altri cholori svariati da quelli, e più chiari e più schuri sechondo che a tte parrà che per tua fantasia possa chomprendere, ché ll'una chosa t'insegnerà l'altra, sì per praticha e ssì per saper d'intelletto. La ragione? Che ciascheduna arte di suo natura è abile e piacevole; che ne piglia se n'à, e simile per lo chontrario. ${ }^{121}$

Kap. 173 [...] Ist die Leinwand schwarz, so kannst du mit einem ziemlich hellen Blau arbeiten, das ist nämlich genügend Bleiweiss und ein wenig Indigo, vermischt, verrieben und a Tempera bereitet, nach dem Gebrauch, den ich dir bei den anderen Farben angegeben habe. Wenn die Leinwand lichtblau ist, nimm Bleiweiss, welches gemahlen und getrocknet und bereitet ist nach der Weise der anderen Farben. Und im Allgemeinen: je nachdem du die Grundfarbe vorfindest, kannst du andere abstechende wählen, mehr hell oder dunkel, wie es dir gutdünkt, und du nach deiner Phantasie verstehen kannst. Denn eine Sache lehrt nämlich die andere, so durch die Praxis und so durch das Wissen des Intellekts. Der Grund ist, weil jede Kunst ihrer Natur nach fähig und gefällig ist, wer danach strebt, erreicht sie, und umgekehrt. ${ }^{122}$

Das »Wissen des Intellekts« erfährt eine Ergänzung durch die Erfahrung der Praxis und diese wird durch das Wissen des Intellekts instruiert. Der Phantasie wird auch Entscheidungskompetenz zugebilligt und zwar in Fällen, in denen rationale Anleitung nicht ausreicht. Pratica und fantasia werden in diesem Zusammenhang gegenüber dem intelletto aufgewertet, ohne dass dessen Bedeutung und Autorität grundsätzlich in Frage gestellt wird. ${ }^{123}$ Eine Neigung, Bedenken gegenüber einer Überschätzung des saper dell'intelletto zu äußern, ist auch in Kap. 104 erkennbar. Hier stellt Cennini fest, dass man allein durch die Lektüre des Libro nicht zu einem guten Maler werden könne. Erforderlich sei Werkstattpraxis. ${ }^{124}$ Erneut betont er dies in Kapitel 67 in Verbindung mit Techniken der Inkarnatmalerei: $\gg \mathrm{Ma}$ veggiendo tu lavorare e pratichare la mano, ti sarebbe più avidente che vederlo per iscrittura. « ${ }^{125}$ Rein intellektuelles Buch- und Studierstubenstudium wird skeptisch beurteilt. Die idealen Leser seines Libro finden den Weg in die Werkstatt. Die Praxis erfordert nach Cennini die Tätigkeit der Phantasie. Phantasie hat hier

121 Cennini, Il libro dell'arte/Ed. Frezzato (2008), 197-198.

122 Cennini, Il libro dell'arte/Übers. Ilg (1888), 123-124. Vgl. den Kommentar von Frezzato, in: Cennnini, Il libro dell'arte/Ed. Frezzato (2008), 198, Anm. 208.

123 Cenninis Betonung des Stellenwerts der pratica dürfte auf Werkstatterfahrung basieren. Beachtenswert ist gleichwohl, dass Konzeptionen praktischen Wissens seit dem 14. Jahrhundert zunehmend von Gelehrten theoretisch reflektiert wurden. Siehe hierzu Lohr (2010), bes. 36-37; zum traditionellen Verständnis von usus, ars und scientia siehe Binding (1994), 967-980.

124 Vgl. hierzu Seiler (2012), 45.

125 Cennini, Il libro dell'arte/Ed. Frezzato (2008), 115; vgl. auch die Formulierungen: „Quando ài la praticha nella mano d'aombrare« (83); »sicchè sia praticho nel occhio tuo di non ghuastare li azzuri buoni per i chattivi« (106). 
im Wesentlichen die Bedeutung des modernen Begriffs »Intuition «. ${ }^{126}$ Gemeint ist sowohl die Fähigkeit durch intuitives Vorgehen Erfahrungswissen zu erwerben wie auch die Fähigkeit, intuitiv Entscheidungen zu treffen. Das Schaffen neuer Gemälde umfasst verschiedene Arbeitsschritte, für die Cennini vielfach intuitives Vorgehen für unerlässlich hält; die zeichnerische Entwurfstätigkeit, das comporre von figure o storie ist nur einer von mehreren solcher Arbeitsschritte. Das seltene Vorkommen des Begriffs Phantasie ${ }^{127}$ liegt nicht zuletzt wohl daran, dass er (im Werkstattjargon nicht verankert und) im Kontext der Malerei neu war. Um in der Praxis erforderliche intuitive Fähigkeiten zu bezeichnen, verwendet Cennini häufiger den ihm offenbar geläufigeren Begriff: sentimento, der allerdings eine spezifische Bedeutung hat. ${ }^{128}$ Sentimento setzt nach Cenninis Verwendung des Wortes die Mitwirkung der auf natürlicher Begabung basierenden Phantasie voraus, bezeichnet aber in erster Linie ein Vermögen, das durch operazione di mano erworben wird und (anders als die Phantasie) auch stetig erweitert werden kann.

Die Malerei wird in Cenninos Libro dell'arte als eine auf Naturnachahmung basierende Kunst ausgewiesen. Ein perfekter Maler kann nur derjenige werden, der aus natürlicher Liebe (amor naturale) Gefallen an ihr findet und mit edler Gesinnung (animo gentile) bestrebt ist, sie gemäß ihrer Wissenschaft (scienza) auszuüben. Ihr rationales Wissen besteht nicht nur in technischem know how, sondern auch in philosophischen Wahrheiten. Dadurch erhält sie einen besonderen Rang unmittelbar unterhalb der Philosophie. Durch präzises Zeichnen von Naturdingen ist es dem Maler möglich, die ihnen inhärente, metaphysische Substanz zu finden und - soweit es ihm seine Fähigkeiten ermöglichen - zu fixieren. Die Formen (disegni), die er sich durch das trovare cose non vedute aneignet, sind keine Erfindungen, sondern besitzen Naturwahrheit. Nur durch seinen in jahrelanger Praxis des Zeichnens erworbenen Formenfundus erlangt er das Vermögen und die Freiheit, Dinge aller Art darzustellen. Gemälde mit Figuren und Historien (figure e storie) basieren auf der Neuzusammensetzung - dem comporre e llegare insieme - naturwahrer Formen. Dieses Komponieren wird als poetischer Modus aufgefasst. Das reproduktive Zeichnen nach der Natur (ritrarre del naturale) wie auch die produktive Hervorbringung neuer Formverbindungen erfordern Phantasie und Intellekt. Cennini fasst Phantasie nicht einseitig als kreatives Vermögen auf, sondern im Anschluss an die mittelalterliche Fakultätenpsychologie als zweifaches Vermögen. Die von ihm reklamierte Lizenz zur freien

126 Vgl. Kobusch, Art. »Intuition« Historisches Wörterbuch der Philosophie, Bd. 4, Sp. 524-540.

127 Cennini, Il libro dell'arte/Ed. Frezzato (2008), 4, 27, 143, 189.

128 Cennini, Il libro dell'arte/Ed. Frezzato (2008), 81, Kap. 28: »chome inchominci aver qualche sentimento nel disegnare $(85)$, Kap. 31: »e seghuita, più volte andando chol tuo pennello, e ghuidalo con sentimero« (114), Kap. 67: »E così, con sentimento ricerchare tutto il viso« (119), Kap. 71: »assettando le pieghe con buon disegnio e sentimento (159); Kap. 137: »schuoprilo piano, con sentimento (162); Kap. 140: »che con sentimento di fantasia e di mano leggiera tu poi in un campo d'oro dare fogliami« (181), Kap. 160: "convien che per te medesimo adoperi sentimento in saperlo ben guidare« (200); Kap. 175: "onde di bisogno è provedersi con sentimento e con buona pratica." 
Erfindung ist in seinem Verständnis der Malerei als scienza fundiert, und die Phantasie als Produktivkraft des Neuen wird in Synergie mit dem Intellekt des Künstlers gedacht. Direkte Rückgriffe auf antike Texte spielen im Libro dell'arte keine Rolle. Als Agent der Transformation antiken Erbes war Cennini alles andere als kreativ, aber er transferierte antikes Theoriegut, das bereits einen langen nachantiken Transformationsprozess durchlaufen hatte, in das Ambiente der spätmittelalterlichen Malerwerkstätten. 


\section{Literaturverzeichnis}

\section{Quellen}

Alain de Lille, Anticlaudianus, hg. v. Robert Bossuat, Paris 1955.

Alberti, Leon Battista, Della Pittura - Über die Malkunst, hg. v. Oskar Bätschmann und Sandra Gianfreda, Darmstadt ${ }^{2} 2007$.

Aristoteles, De anima. Über die Seele, hg. v. Gernot Krapinger, Stuttgart 2011.

Aristoteles, De anima, ed. by William David Ross, Oxford 1956.

Boccaccio, Giovanni, Das Decameron, aus dem Italienischen übersetzt, mit Kommentar und Nachwort v. Peter Brockmeier, Stuttgart 2012.

Boccaccio, Giovanni, Tutte le opere di Giovanni Boccaccio, VII-VIII: Genealogie deorum gentilium, De montibus, silvis, fontibus, lacubus, fluminibus, stagnis seu paludibus, De diversis nominibus maris, Mailand 1998.

Boccaccio, Giovanni, Tutte le opere di Giovanni Boccaccio, IV: Decameron, hg. v. Vittore Branca, Mailand ${ }^{3} 1996$.

Bonaventura, Itinerarium mentis in deum. De reductione artium ad theologiam/Pilgerbuch der Seele zu Gott. Die Zurückführung der Künste auf die Theologie, eingeleitet, übersetzt und erläutert v. Julian Kaup OFM, München 1961.

Doctoris Seraphici S. Bonaventurae, Opera omnia, edita studio et cura pp. Collegii a S. Bonaventura, 10 Bde., Quaracchi: Collegium S. Bonaventurae 1882-1902.

Buti, Francesco, Commento di Francesco da Buti sopra la Divina Comedia di Dante Allighieri, hg. v. Crescentino Giannini, Pisa 1858 (ND 1989), Bd. 2.

Cennini, Cennino, Il libro dell'arte, hg. v. Fabio Frezzato, Vicenza ${ }^{4} 2008$.

Cennini, Cennino, Il libro dell'arte, hg. und kommentiert v. Mario Serchi, Florenz 1999.

Cennini, Cennino, Il libro dell'arte, hg. und kommentiert v. Mario Serchi, Florenz 1991.

Cennini, Cennino, The Craftman's Handbook: The Italian ,Il libro dell'arte`, transl. by Daniel V. Thompson Jr., New York 1933 (Reprint 1960).

Cennini, Cennino, The Craftman's Handbook, transl. by Daniel V. Thompson Jr., New York 1933.

Cennini, Cennino, Handbüchlein der Kunst, neu übers. und hg. v. Willibrord Verkade, Straßburg 1916.

Cennini, Cennino, Das Buch von der Kunst, mit Einleitung, Noten und Register versehen v. Albert Ilg (Quellenschriften für Kunstgeschichte und Kunsttechnik des Mittelalters und der Renaissance 1), Wien 1888.

Cennini, Cennino, Il libro dell'arte, hg. v. Gaetano Milanesi/Carlo Milanesi, Florenz 1859.

Dante Alighieri, La Commedia/Die Göttliche Komödie, II. Purgatorio/Läuterungsberg, Italienisch/Deutsch, in Prosa übers. und kommentiert v. Hartmut Köhler, Stuttgart 2011.

Dante Alighieri, Das Gastmahl, Erstes Buch, übersetzt v. Thomas Ricklin, kommentiert v. Francis Chevenal, Hamburg 1996.

Dante Alighieri, Das Gastmahl, Drittes Buch, übersetzt v. Thomas Ricklin, kommentiert v. Francis Chevenal, Hamburg 1998.

Dante Alighieri, Die göttliche Komödie, übers. v. Hermann Gmelin, Kommentar, II. Teil: Der Läuterungsberg, Stuttgart ${ }^{2} 1968$. 
Dante Alighieri, Die göttliche Komödie, deutsche Übertr. v. Ida und Walther von Wartburg, Zürich 1963.

Ghiberti, Lorenzo, I commentarii (Biblioteca Nazionale Centrale di Firenze, II, I, 333), hg. v. Lorenzo Bartoli, Florenz 1998.

Guilelmus Durandus, Rationale divinorum officiorum, hg. v. D. Davril und T.M. Thibodeu (Corpus christianorum Continuatio Mediaevalis 140), Turnhout 1995.

Horaz, Sämtliche Werke, hg. v. Hans Färber, München/Zürich 1985.

Isidor von Sevilla, Die Enzyklopädie des Isidor von Sevilla, übers. und mit Anmerkungen versehen v. Lenelotte Möller, Wiesbaden 2008.

Isidor von Sevilla, Etymologiarum sive originum libri XX, ed. by Wallace Martin Lindsay, 2 Bde., Oxford 1987 (ND 1991).

Michelangelo, Die Dichtungen des Michelangelo Buonarotti, hg. v. Carl Frey, Zweite Auflage, Berlin 1964.

Richard von St. Victor, Benjamin Maior, in: Marc-Aeilko Aris, Contemplatio. Philosophische Studien zum Traktat Benjamin Maior des Richard von St. Victor, mit einer verbesserten Edition des Textes (Fuldaer Studien 6), Frankfurt a. M. 1996.

\section{Forschungsliteratur}

Aris, Marc-Aeilko, Contemplatio. Philosophische Studien zum Traktat Benjamin Maior des Richard von St. Victor, mit einer verbesserten Edition des Textes (Fuldaer Studien 6), Frankfurt a. M. 1996.

Arne, Moritz (Hg.), Ars imitatur naturam: Transformationen eines Paradigmas menschlicher Kreativität im Übergang vom Mittelalter zur Neuzeit, Münster 2010.

Arnulf, Arwed (Hg.), Kunstliteratur in Antike und Mittelalter: Eine kommentierte Anthologie, Darmstadt 2008.

Arnulf, Arwed, Architektur- und Kunstbeschreibungen von der Spätantike bis zum 16. Jahrhundert, Berlin 2004.

Assunto, Rosario, Die Theorie des Schönen im Mittelalter, Köln 1982.

Assunto, Rosario, La critica d'arte nel pensiero Medievale, Mailand 1961.

Ausst.-Kat. "Fantasie und Handwerku. Cennino Cennini und die Tradition der toskanischen Malerei von Giotto bis Lorenzo Monaco, hg. v. Wolf-Dietrich Löhr/Stefan Weppelmann, Berlin 2008.

Bautier, Anne-Marie, »Phantasia-imaginatio. De l'image à l'imaginaire dans les textes du haut Moyen Âge«, in: Phantasia-Imaginatio. $V^{\circ}$ Colloquio Internazionale del Lessico Intellettuale Europeo, Rom 9.-11. Januar 1986, hg. v. Marta Fattori/Massimo Luigi Bianchi, Rom 1988, 81-104.

Baxandall, Michael, Giotto and the Orators. Humanist Observers of Painting in Italy and the Discovery of Pictorial Composition. 1350-1450, Oxford 1971.

Belting, Hans, »Bild und Schatten. Dantes Bildtheorie im Wandel zur Kunstheorie«, in: Ders.: Bild-Anthropologie. Entwürfe für eine Bildwissenschaft, München 2001, 189 211.

Belting, Hans, »Über Phantasie und Kunst«, in: Homo pictor, hg. v. Gottfried Boehm, Leipzig 2001, 143-155. (= Belting 2001a)

Bialostocki, Jan, »The Renaissance Concept of Nature and Antiquity«, in: The Renaissance and Manierism, Acts of the Twentieth International Congress of the History of 
Art 2 (1963), 19-30 (wiederabgedruckt in: Ders. The Message of Images. Studies in the History of Art, Wien 1988, 64-68).

Binding, Günther, »Ein Beitrag zumVerständnis von usus und ars im 11./12. Jahrhundert«, in: Scientia und ars im Hoch- und Spätmittelalter 2 (Miscellanea Medievalia, 22/2), hg. Ingrid v. Craemer-Ruegenberg/Andreas Speer, Berlin/New York 1994, 967-980.

Blume, Dieter, »Die Täuschung der Sinne oder die Intellektualität der Malerei, Bild und Poesie bei Giovanni Boccaccio«, in: Wirtschaft und Wissenschaft, hg. v. Stifterverband für die Deutsche Wissenschaft, H. 2, 1996, 37-44 (sowie in: Jenaer Universitätsreden, Bd. 10, Phil. Fak., Antrittsvorlesungen Bd. IV, Jena 2003, 41-61).

Bolland, Andrea, »Art and Humanism in Early Renaissance Padua: Cennini, Vergerio and Petrarch«, in: Renaissance Quarterly 49/3 (1996), 469-487.

Boscovits, Miklós, „Cennino Cennini - pittore nonconformista«, in: Mitteilungen des Kunsthistorischen Instituts in Florenz 17 (1973), 202-222.

Bundy, Muray Wright, The Theory of Imagination in Classical and Medieval Thought, Urbana, Ill. 1927.

Busa, Roberto, SI, »De phantasia et imaginatione iuxta S. Thomam«, in: PhantasiaImaginatio. $V^{\circ}$ Colloquio Internazionale del Lessico Intellettuale Europeo, Rom 9.11. Januar 1986, hg. v. Marta Fattori/Massimo Luigi Bianchi, Rom 1988, 131-152.

Carruthers, Mary J., »Moving Images in the Mind's Eye«, in: The Mind's Eye. Art and Theological Argument in the Middle Ages, ed. by Jeffrey F. Hamburger/ Anne-Marie Bouché, Princeton 2006, 286-305.

Chastel André, »Le dictum Horatii quidlibet audendi potestas et les artists«, in: Fables, formes, figures, Bd. 1, Paris 1988, 363-376.

Chastel, André, »Le ssi come gli piace « de Cennino Cennini«, in: Scritti di storia dll'arte in onore di Ugo Procacci, Bd. 1, Mailand 1977, 32-34.

Chenu, Marie Dominique, Imaginatio. Note de lexicographie philosophique médiévale. Miscellanea Giovanni Mercato, Bd. 2, Letteratura medioevale, Studi e testi 122, Vatikanstadt 1946.

Ciccuto, Marcello, »Era venuta ne la mente mia: visione nella $>$ Vita nova e imagine nel pensiero di Dante«, in: Icone delle parola: immagine e scrittura nella letteratura delle origini, hg. v. Marcello Ciccuto, Modena 1995, 95-111.

Curtius, Ernst Robert, Europäische Literatur und lateinisches Mittelalter, München ${ }^{9} 1978$.

Dresdner, Albert, Die Entstehung der Kunstkritik, München 1915 (ND 1968).

Eco, Umberto, Kunst und Schönheit im Mittelalter, München/Wien 1991.

Eusterschulte, Anne: »Imitatio naturae. Naturverständnis und Nachahmungslehre in den Malereitraktaten der frühen Neuzeit«, in: Künste und Natur in Diskursen der Frühen Neuzeit, hg. v. Hartmut Laufhütte, 2 Bde., Wiesbaden 2000, Bd. 2, 791-807.

Feser, Sabine, »Plastizität«, in: Giorgio Vasari. Kunstgeschichte und Kunstheorie. Eine Einführung in die Lebensbeschreibung berühmter Künstler. Neu übers. v. Victoria Lorini, hg., eingeleitet und kommentiert v. Matteo Burioni/Sabine Feser, 3. Aufl., Berlin 2010, 276-278.

Flasch, Kurt, »Ars imitatur naturam. Platonischer Naturbegriff und mittelalterliche Philosophie der Kunst«, in: Parusia. Studien zur Philosophie Platons und zur Problemgeschichte des Platonismus. Festgabe für Johannes Hirschberger, hg. v. Kurt Flasch, Frankfurt a. M. 1965, 265-306.

Flury, Peter, »Phantasia und imaginatio im Bereich des antiken Latein«, in: PhantasiaImaginatio. $V^{\circ}$ Colloquio Internazionale del Lessico Intellettuale Europeo, Rom 9.11. Januar 1986, hg. v. Marta Fattori und Massimo Luigi Bianchi, Rom 1988, 69-79. 
Gilbert, Creighton E., »Boccaccio's Devotion to Artists and Art«, in: Poets Seeing Artists ' Work. Instances in the Italian Renaissance, Florenz 1991, 49-65

Gilbert, Creighton E., »Boccaccio Looking at Actual Frescoes«, in: Poets Seeing Artists ' Work. Instances in the Italian Renaissance, Florenz 1991, 167-196. (= Gilbert 1991a)

Ginzburg, Carlo, „Das Nachäffen der Natur. Reflexionen über eine mittelalterliche Metapher«, in: Fälschungen. Zur Autorschaft und Beweis in Wissenschaften und Künsten, hg. v. Anne Kathrin Reulecke, Frankfurt a. M. 2006, 95-122.

Gramaccini, Noberto, »Cennino Cennini e il suo >Trattato della Pittura««, in: Res publica litterarum 10 (1987), 143-151.

Gramaccini, Noberto, »Das genaue Abbild der Natur - Riccios Tiere und die Theorie des Naturabgusses seit Cennino Cennini«, in: Ausst.-Kat. Natur und Antike in der Renaissance (Austellung im Liebighaus Museum alter Plastik, Frankfurt, 5. Dezember 1985-2. März 1986), Frankfurt 1985, 198-225.

Grassi, Luigi, Teorici e storia della critica d'arte. Prima parte: Dall'antichità a tutto il Cinquecento con due saggi introduttivi, Rom 1985.

Gründler, Hana, »Die Wege des Saturn. Vasari und die Melancholie«, in: Le Vite del Vasari. Genesi, topoi, ricezione/Die Vite Vasaris. Entstehung, Topoi, Rezeption, hg. v. Katja Burzer/Charles Davis/Sabine Feser/Alessandro Nova, Venedig 2010, 71-82.

Hamesse, Jacqueline, »Imaginatio et phantasia chez les auteurs philosophiques du $12 \mathrm{e}$ et du $13 \mathrm{e}$ siècle«, in: Phantasia-Imaginatio. $V^{\circ}$ Colloquio Internazionale del Lessico Intellettuale Europeo, Rom 9.-11. Januar 1986, hg. v. Marta Fattori/Massimo Luigi Bianchi, Rom 1988, 153-184.

Harvard, Ruth E., The Inward with Psychological Theory in the Middle Ages, London 1975.

Historisches Wörterbuch der Philosophie, hg. v. Joachim Ritter/Karlfried Gründer, 13. Bde., Basel 1971-2007.

Janson, Horst W., Apes and Ape Lore in the Middle Ages and the Renaissance, London 1952.

Kablitz, Andreas, »Jenseitige Kunst oder Gott als Bildhauer. Die Reliefs in Dantes Purgatorio (Purg. X-XII)«, in: Mimesis und Simulation, hg. v. Andreas Kablitz/Gerd Neumann, Freiburg im Breisgau 1998, 309-356.

Kablitz, Andreas, »Fiktion und Bedeutung: Dantes Vita Nuova und die Tradition der volkssprachlichen Minnelyrik«, in: Fiktion und Fiktionalität in den Literaturen des Mittelalters, hg. v. Ursula Peters/Rainer Warning, München 2009, 339-362.

Kämmerlings, Richard, »Mystica arca. Zur Erkennntislehre Richards von St. Viktor in De gratia contemplationis«, in: Mittelalterliches Kunsterleben nach Quellen des 11. bis 13. Jahrhunderts, hg. v. Günther Binding/Andreas Speer, Stuttgart 1994, 76-100.

Kemp, Martin, Behind the Picture: Art and Evidence in the Italian Renaissance, New Haven/London 1997.

Klier, Andrea, ")Quello che non è sia،. Ornamentale Grenzzustände auf den Keramiken von Bernard Palissy und Saint-Pochaire«, in: Curiosa Poliphili. Festgabe für Horst Bredekamp zum 60. Geburtstag, hg. v. Nicole Hegener/Claudia Lichte/Bettina Marten, Leipzig 2007, 18-25.

Klier, Andrea, Fixierte Natur. Naturabguss und Effigies im 16. Jahrhundert, Berlin 2004.

Kobusch, Theo, Art. »Philosophie«, E. Mittelalter, in: Historisches Wörterbuch der Philosophie, hg. v. Joachim Ritter/Karlfried Gründer, Basel 1989, Bd. 7, 633-656.

Kobusch, Theo, Die Philosophie des Hoch- und Spätmittelalters (Geschichte der Philosophie, Bd. 5, hg. v. Wolfgang Röd), München 2011. 
Kris, Ernst/Kurz, Otto, Die Legende vom Künstler, Frankfurt a. M. 1980.

Kruse, Christiane, »Fleisch werden - Fleisch malen: Malerei als >incarnazione «. Mediale Verfahren des Bildwerdens im Libro dell'arte von Cennino Cennini«, in: Zeitschrift für Kunstgeschichte 63 (2000), 305-325.

Kruse, Christiane, Wozu Menschen malen: historische Begründungen eines Bildmediums, München 2003.

Kruse, Christiane, »Schatten an der Wand - oder: Was ist und leistet ein Bild? Bildkonzepte der Malerei von Platon bis Boccaccio«, in: Kann das Denken malen? Philosophie und Malerei in der Renaissance, hg. v. Inigo Bocken/Tilman Borsche, München 2010, 275-298.

Krüger, Klaus, Das Bild als Schleier des Unsichtbaren. Ästhetische Illusion in der Kunst der frühen Neuzeit in Italien, München 2001.

Kuhn, Rudolf, »Cennino Cennini. Sein Verständnis dessen, was die Kunst in der Malerei sei, und seine Lehre vom Entwurfs- und vom Werkprozess«, in: Zeitschrift für Ästhetik und Kunstwissenschaft 36 (1991), 104-153.

Latham, Ronald, »Imagination in British Medieval Latin Writers«, in: PhantasiaImaginatio. $V^{\circ}$ Colloquio Internazionale del Lessico Intellettuale Europeo, Rom 9.11. Januar 1986, hg. v. Marta Fattori/Massimo Luigi Bianchi, Rom 1988, 105-115.

Longhi, Roberto, »Letteratura artistica e Letteratura nazionale«, in: Paragone 33 (1952), 7-14.

Lohr, Charles, »Aristotelian >scientia and the medieval >arts Transformationen eines Paradigmas menschlicher Kreativität im Übergang vom Mittelalter zur Neuzeit, hg. v. Moritz Arne, Münster 2010, 29-37.

Löhr, Wolf-Dietrich, »Von Gottes I zu Giottos O. Schöpferhand und Künstlerkörper zwischen Mittelalter und Früher Neuzeit«, in: Auge und Hand, hg. v. Johannes Bilstein/Guido Reuter, Oberhausen 2011, 51-76.

Löhr, Wolf-Dietrich, »>Glieder in der Kunst der Malerei`: Cennino Cenninis Genealogie und die Suche nach Kontinuität zwischen Handwerkstradition, Werkstattpraxis und Historiographie, zusammen mit Stefan Weppelmann«, in: Ausst.-Kat. Fantasie und Handwerk. Cennino Cennini und die Tradition der toskanischen Malerei von Giotto bis Lorenzo Monaco (Gemäldegalerie Berlin, 10. Januar-13. April 2008), hg. v. Wolf-Dietrich Löhr/Stefan Weppelmann, München 2008, 12-43.

Löhr, Wolf-Dietrich, »Handwerk und Denkwerk des Malers. Kontexte für Cenninis Theorie der Praxis«, in: Ausst.-Kat. Fantasie und Handwerk. Cennino Cennini und die Tradition der toskanischen Malerei von Giotto bis Lorenzo Monaco (Gemäldegalerie Berlin, 10. Januar-13. April 2008), hg. v. Wolf-Dietrich Löhr/Stefan Weppelmann, München 2008, 152-176. (= Löhr 2008a)

Löhr, Wolf-Dietrich, »Dantes Täfelchen, Cenninis Zeichenkiste. Ritratto, disegno und fantasia als Instrumente der Bilderzeugung im Trecento«, in: Das Mittelalter. Perspektiven mediävistischer Forschung (Zeitschrift des Mediävistenverbandes) 13 (2008), 148-179. (= Löhr 2008b)

Löhr, Wolf-Dietrich, „Disegnia sechondo che huoi. Cennino Cennini e la fantasia artistica«, in: Linea I. Grafie di immagini tra Quattrocento e Cinquecento, hg. v. Marzia Faietti/Gerhard Wolf, Venedig 2008, 163-190. (= Löhr 2008c)

Magagnato, Licisco, »Introduzione «, in: Cennino Cennini, Il Libro dell'Arte, kommentiert und mit Anmerkungen v. Franco Brunello und mit einer Einleitung v. Licisco Magagnato, Vicenza 1982, V-XXX. 
Martin, Frank, »>Disegno< versus spraticaく. Cennino Cenninis Kapitel über die Glasmalerei im kunsttheoretischen Kontext«, in: Le vitrail et les traités du Moyen Âge à nos jours. Actes du XXIIIe colloque international du Corpus Vitrearum (Tours 3.-7. Juli 2006), hg. v. Michel Hérold/Karine Boulanger, Bern (u.a.) 2008, 45-60.

Marian, Valerio, »Dante e Giotto«, in: Giotto e Dante, hg. v. Gizzi Corrado, Mailand 2001, 77-92.

Meier, Christel, »Malerei des Unsichtbaren. Über den Zusammenhang von Erkenntnistheorie und Bildstruktur im Mittelalter", in: Text und Bild, Bild und Text (Germanistische Symposion-Berichtbände II), DFG-Symposion 1988, hg. v. Wolfgang Harms, Stuttgart 1990, 35-65.

Milizia, Umberto, La pittura di Dante. La concezione delle arti figurative in Dante, Rom 2000.

Panofsky, Erwin, Idea. Ein Beitrag zur Begriffsgeschichte der älteren Kunstgeschichte, 3. Aufl., Berlin 1924 (ND 1975).

Pardo, Mary, »Giotto and the >Things Not Seen in the Shadow of Natural Ones «, in: Artibus et Historiae 18, 36 (1997), 41-53.

Pardo, Mary, »Memory, Imagination, Figuration: Leonardo da Vinci and the Painter's Mind «, in: Images of Memory: On Remembering and Representation, ed. by Susanne Küchler/Walter Melion, Washington 1991, 47-73, 212-224.

Perrig, Alexander, »Vom Zeichnen und von der künstlerischen Grundausbildung im 13. bis 16. Jahrhundert«, in: Die Kunst der italienischen Renaissance. Architektur Skulptur-Malerei-Zeichnung, hg. v. Ralf Toman, Köln 1994, 416-440.

Pfisterer, Ulrich, »Cennino Cennini und die Idee des Kunstliebhabers«, in: Grammatik der Kunstgeschichte: Sprachproblem und Regelwerk im >Bild-Diskurs`, Oskar Bätschmann zum 65. Geburtstag, hg. v. H. Locher/Peter Schneemann, Berlin 2008, 95-117.

Pfisterer, Ulrich, Donatello und die Entdeckung der Stile 1430-1445, München 2002.

Pfisterer, Ulrich (Hg.), Die Kunstliteratur in der italienischen Renaissance. Eine Geschichte in Quellen, Stuttgart 2002. (Pfisterer 2002a)

Pfisterer, Ulrich, »Künstlerische potestas audendi und licentia im Quattrocento - Benozzo Gozzoli, Andrea Mantegna, Bertoldo di Giovanni«, in: Römisches Jahrbuch der Bibliotheca Hertziana 31 (1996), 107-148.

Phantasia-Imaginatio. $V^{\circ}$ Colloquio Internazionale del Lessico Intellettuale Europeo, Rom 9.-11. Januar 1986, hg. v. Marta Fattori und Massimo Luigi Bianchi, Rom 1988.

Picone, Michelangelo, »Il cimento delle arti nella Commedia. Dante nel girone die superbi«, in: Dante e le arti visive, hg. v. Maria Monica Donato/Lucia Battaglia Ricci/ Michelangelo Picone/Giuseppa Z. Zanichelli, Mailand 2006, 81-107.

Prandi, Adriano, »L'attesa dell'arte nuova dal Boccaccio al Cennini«, in: $L$ 'attesa dell'età nuova della spiritualità delle fine del Medioevo (Convegno del centro di Studi sulla Spiritualità Medioevale II), Todi 1962, 338-369.

Puttfarken, Thomas, The Discovery of Pictorial Composition. Theories of Visual Order in Painting 1400-1800, New Haven/London 2000.

Rak, Michele, Art. »Fantasia«, in: Enciclopedia Dantesca, hg. v. Umberto Bosco, Bd. 2, Rom 1970, 793-794.

Regn, Gerhard, »Gott als Dichter: Die Wirklichkeit der Fiktion in Dantes Paradiso«, in: Fiktion und Fiktionalität in den Literaturen des Mittelalters, hg. v. Ursula Peters/Rainer Warning, München 2009, 365-385.

Schapiro, Meyer, »From Mocarabic to Romanesque in Silos«, in: The Art Bulletin 21 (1939), 314-374. 
Schapiro, Meyer, »Munuscula Diaboli, The Symbolism of the Merode Altarpiece«, in: The Art Bulletin 27 (1945), 182-187.

Schlosser, Julius von, Die Kunstliteratur, Wien 1924.

Scholz, Oliver Robert, Art. »Bild«, in: Ästhetische Grundbegriffe, Studienausgabe hg. v. Karlheinz Barck, Martin Fontius/Dieter Schlenstedt/Burkhart Steinwachs/Friedrich Wolfzettel, Bd. 1, Stuttgart/Weimar 2000/2010, 618-669.

Seiler, Peter, "Giotto - das unerreichte Vorbild? Elemente antiker imitatio auctorumLehren in Cennino Cenninis Libro dell'arte«, in: Imitatio als Transformation. Theorie und Praxis der Antikennachahmung in der frühen Neuzeit, hg. v. Ursula Rombach/Peter Seiler, Berlin 2012.

Spinosa, Giacinta, »Phantasia e imaginatio nell'Aristotele latino«, in: PhantasiaImaginatio. $V^{\circ}$ Colloquio Internazionale del Lessico Intellettuale Europeo, Rom 9.11. Januar 1986, hg. v. Marta Fattori/Massimo Luigi Bianchi, Rom 1988, 117-133.

Spruit, Leen, Species intelligibili. From Perception to Knowledge, 2 Bde, Leiden 1996.

Stoichita, Victor I., A Short History of the Shadow, London 1997.

Summers, David, Michelangelo and the Language of Art, Princeton 1981.

Tarr, Roger, »Cennino Cennini, Italian Artist and Writer«, in: Key Writers on Art: From Antiquity to the Nineteenth Century, ed. by Chris Murray, London 2003, 38-44.

Tripps, Johannes, "'Nimm Steine, rau und nicht gereinigt. Gebirge als kunsttheoretisches Studienobjekt in der Malerei des Trecento«, in: Ausst.Kat. Fantasie und Handwerk. Cennino Cennini und die Tradition der toskanischen Malerei von Giotto bis Lorenzo Monaco, hg. v. Wolf-Dietrich Löhr/Stefan Weppelmann, Berlin 2008, 109-119.

Vasoli, Cesare, Art. »Intelletto«, in: Enciclopedia Dantesca, hg. v. Umberto Bosco, Bd. 4, Rom 1971, 464468.

Venturi, Lionello, Storia della critica d'arte, Turin 1964.

Venturi, Lionello, »La critica d'arte alla fine del Trecento. Filippo Villani e Cennino Cennini«, in: L'arte 28/4 (1925), 233-244.

Vesco, Giacomo, »Leon Battista Alberti e la critica d'arte in sul principio del Rinascimento", in: L'arte. Rivista di storia dell'arte medioevale e moderna 22 (1919), 57-71, 95-104, 136-214.

Vöhringer, Christian (Hg.), Kunstliteratur der Neuzeit. Eine kommentierte Anthologie, Darmstadt 2010.

Warnke, Martin, »Chimären der Phantasie«, in: Nah und Fern zum Bilde. Beiträge zu Kunst und Kunsttheorie, hg. v. Michael Diers, Köln 1997, 259-277.

Warnke, Martin, »Praxisfelder der Kunsttheorie. Über die Geburtswehen des Individualstils«, in: Nah und Fern zum Bilde. Beiträge zu Kunst und Kunsttheorie, hg. v. Michael Diers, Köln 1997, 16-39. (= Warnke 1997a)

Watson, Paul F., »The Cement of Fiction: Giovanni Boccaccio and the Painters of Florence $\ll$, in: Modern Language Notes 99 (1984), 43-64.

Wels, Volkhard, »Zur Vorgeschichte des Begriffs der >kreativen Phantasie««, in: Zeitschrift für Ästhetik und Allgemeine Kunstwissenschaft 50/1 (2005), 199-226.

Wolf, Gerhard, Schleier und Spiegel. Traditionen des Christusbildes und die Bildkonzepte der Renaissance, München 2002. 